\title{
Nef functions in BLT mice to enhance HIV-1 replication and deplete $\mathrm{CD} 4^{+} \mathrm{CD} 8^{+}$thymocytes
}

\author{
Wei Zou', Paul W Denton ${ }^{1}$, Richard L Watkins ${ }^{1}$, John F Krisko ${ }^{1}$, Tomonori Nochi ${ }^{1}$, \\ John L Foster ${ }^{1}$ and J Victor Garcia ${ }^{1,2^{*}}$
}

\begin{abstract}
Background: The outcome of untreated HIV-1 infection is progression to AIDS and death in nearly all cases. Some important exceptions are the small number of patients infected with HIV-1 deleted for the accessory gene, nef. With these infections, disease progression is entirely suppressed or greatly delayed. Whether Nef is critical for high levels of replication or is directly cytotoxic remains controversial. The major problem in determining the role of Nef in HIV/AIDS has been the lack of tractable in vivo models where Nef's complex pathogenic phenotype can be recapitulated.

Results: Intravenous inoculation (3000 to 600,000 TCIU) of BLT humanized mice with HIV-1 LAl reproducibly establishes a systemic infection. HIV-1 LAI (LAI) replicates to high levels (peak viral load in blood 8,200,000 1 1,800,000 copies of viral RNA/ml, range 3,600,000 to 20,400,000; $n=9$ ) and exhaustively depletes $C D 4^{+} T$ cells in blood and tissues. $C D 4^{+} C D 8^{+}$ thymocytes were also efficiently depleted but $\mathrm{CD} 4^{+} \mathrm{CD} 8$ thymocytes were partially resistant to cell killing by LAl. Infection with a nef-deleted LAI (LAINefdd) gave lower peak viral loads $(1,220,000 \pm 330,000$, range 27,000 to 4,240,000; $n=17)$. For fourteen of seventeen LAINefdd-infected mice, there was little to no loss of either CD4 ${ }^{+} \mathrm{T}$ cells or thymocytes. Both LAland LAINefdd-infected mice had about $8 \%$ of total peripheral blood $C D 8^{+} T$ cells that were $C D 38^{+} H L A-D R^{+}$compared $<1 \%$ for uninfected mice. Three exceptional LAINefdd-infected mice that lost CD4 ${ }^{+}$T cells received 600,000 TCIU. All three exhibited peak viral loads over 3,000,000 copies of LAINefdd RNA/ml. Over an extended time course, substantial systemic $C D 4^{+} T$ cell loss was observed for the three mice, but there was no loss of $\mathrm{CD}^{+} \mathrm{CD}^{+}$or $\mathrm{CD} 4^{+} \mathrm{CD} 8^{-}$thymocytes.

Conclusion: We conclude Nef is necessary for elevated viral replication and as a result indirectly contributes to $\mathrm{CD}^{+} \mathrm{T}$ cell killing. Further, Nef was not necessary for the activation of peripheral blood CD8 ${ }^{+} T$ cells following infection. However, $\mathrm{CD}^{+} \mathrm{CD}^{+}$thymocyte killing was dependent on Nef even in cases of elevated LAINefdd replication and T cell loss. This depletion of thymic T cell precursors may be a significant factor in the elevated pathogenicity of CXCR4 trophic HIV-1.
\end{abstract}

Keywords: HIV-1, Nef, Humanized mouse, Replication, Pathogenicity

\section{Background}

HIV-1 infection leads to the near total loss of $\mathrm{CD} 4^{+} \mathrm{T}$ cells and results in immune incompetence [1,2]. Nef is considered to be a critical inducer of pathogenicity for HIV-1, because there are several reported cases of human infection by HIV-1 lacking a functional nef that failed to develop AIDS for twelve years or more [3-9]. Also, support for an important role for simian immunodeficiency virus Nef in pathogenesis and disease progression comes from elegant experiments performed in non-

\footnotetext{
*Correspondence: Victor_Garcia@med.unc.edu

'Division of Infectious Diseases, Center for AIDS Research, University of North Carolina, Chapel Hill, NC 27599-7042, USA

${ }^{2}$ Division of Infectious Diseases, UNC Center for AIDS Research, 2042 Genetic Medicine, Campus Box 7042, Chapel Hill, NC 27599-7042, USA
}

human primates where the absence of Nef resulted in delayed disease progression $[10,11]$.

In vivo and ex vivo models of HIV-1 infection have been utilized to assess the role of Nef in viral replication and pathogenesis. Transgenic mouse models have demonstrated that Nef is the only HIV-1 protein that has direct pathogenic effects in mice [12-14]. Results from an HIV-1 infection model employing ex vivo cultures of human tonsil suggested a role for Nef as a replication factor [15-18]. Ex vivo experiments with human fetal thymus organ culture (HF-TOC) found that nef functioned as a pathogenic factor that does not enhance replication [19]. The findings with HF-TOC were confirmed with the SCID-hu thy/liv implant model in which infection can be extended beyond the maximum two-week duration for most ex vivo models 
[19]. Other groups found a dual role for Nef in HIV-1 infection of SCID-hu thy/liv implants as a replication and a pathogenesis factor [20,21]. Aldrovandi et al. found the impact of nef-deleted HIV-1 on viral replication to be dependent on the initial dose [22,23].

To address Nef's role in HIV-1 pathogenesis during prolonged systemic infection, we have investigated the impact of inactivating nef on HIV-1 infection in vivo using BLT humanized mice [24-27]. This advanced model for human immune system reconstitution combines human stem cell engraftment in bone marrow with a human fetal liver/thymus implant producing a full range of systemically disseminated human immune cells including $\mathrm{B}$ cells, monocytic cells, dendritic cells and $\mathrm{T}$ cells. Human thymocyte education occurs within the implanted thymus which is a fully human cellular compartment [24,26,28]. BLT humanized mice have both human $\mathrm{T}$ cells and human thymocytes that can be infected simultaneously. This distinction establishes the BLT mouse model as a novel system for determining in vivo pathogenesis attributable to HIV-1 accessory genes. We inoculated mice with the strictly CXCR4tropic virus, HIV-1 $1_{\text {LAI }}$ (LAI), to maximize the pathogenic impact of the infection [29,30]. At three different inoculums in BLT mice, LAI rapidly depletes human $\mathrm{CD}^{+} \mathrm{T}$ cells in the peripheral blood and in tissues and eliminates $\mathrm{CD}^{+} \mathrm{CD}^{+}$thymocytes from the implanted human thymic tissue [27].

At a low intravenous inoculum, we found nef-defective LAI to be greatly delayed for replication with lower peak viral loads relative to wild-type LAI. There was minimal $\mathrm{CD}^{+} \mathrm{T}$ cell and $\mathrm{CD} 4^{+} \mathrm{CD} 8^{+}$thymocyte killing. At a high dose, the delay in nef-defective LAI replication was largely lost and in a few exceptional cases there was gradual loss of $\mathrm{CD}^{+} \mathrm{T}$ cells in blood and tissues. However, in no case did nef-defective LAI infection result in loss of thymocytes.

With these findings we have established the humanized BLT mouse model as highly appropriate for directly studying the complex role of Nef in processes that are critical for disease progression during HIV-1 infection. Our results suggest an indirect role for Nef in $\mathrm{T}$ cell killing and a direct role for Nef in loss of thymic function in HIV-1 infection [19,31,32].

\section{Results}

\section{Defining the course of infection in the BLT humanized} mouse with the highly pathogenic HIV-1 LAI

The goal of these experiments was to investigate the role of Nef in the pathogenic sequela of HIV-1 $1_{\text {LAI }}$ (LAI) in vivo. For this purpose we used the BLT humanized mouse model that has been shown to recapitulate key aspects of HIV infection in humans [27,33,34]. We first investigated the relationship between the dose of viral inoculum and the course/outcome of LAI infection. The intravenous doses chosen were 3000 TCIU, 30,000 TCIU and $600,000 \mathrm{TCIU}$ which correspond to $0.23 \mathrm{ng}, 2.3 \mathrm{ng}$ and $45 \mathrm{ng}$ of $\mathrm{p} 24^{\mathrm{gag}}$. We designated $3000 \mathrm{TCIU}$ as a low dose compared to inoculums of 12.5 and $25 \mathrm{ng}$ of $\mathrm{p} 24^{\text {gag }}$ directly injected into the thy/liv implant of SCID-hu mice in previously published studies [22,23]. When BLT mice were infected intravenously with a low dose of LAI (3000 TCIU), all mice became systemically infected. The virus replicated to a high level by two weeks and ultimately exceeded $10^{6}$ copies of viral $\mathrm{RNA} / \mathrm{ml}$ in peripheral blood (Figure 1A). After the viral load reached about $10^{6}$ copies of HIV RNA/ml, a decrease in peripheral blood $\mathrm{CD}^{+} \mathrm{T}$ cells ensued (Figure $1 \mathrm{~B}$ ). $\mathrm{CD}^{+} \mathrm{T}$ cell depletion proceeded such that $\mathrm{CD}_{4}^{+} \mathrm{T}$ cell levels were very low by ten weeks. By contrast, naïve control mice had stable $\mathrm{CD}^{+}{ }^{+} \mathrm{T}$ cell levels in the peripheral blood for the entire period of the experiment (Figure 1B). Increasing the infectious dose of virus by 10 -fold (30,000 TCIU) gave an acceleration of viral production with $10^{6}$ copies of RNA/ $\mathrm{ml}$ appearing in blood by two weeks (Figure 1A). Concomitant with the earlier appearance of viral RNA, there was a more rapid decline of $\mathrm{CD}^{+} \mathrm{T}$ cells (Figure 1B). Finally, a further 20 -fold increase in viral inoculum $\left(6 \times 10^{5}\right.$ TCIU) gave massive viral replication, yielding $10^{7}$ copies of viral $\mathrm{RNA} / \mathrm{ml}$ of blood (Figure $1 \mathrm{~A}$ ). There was also a drastic loss of $\mathrm{CD}^{+} \mathrm{T}$ cells (Figure $1 \mathrm{~B}$ ) by 3 weeks. These results demonstrate that intravenous infection of BLT mice with LAI, at even the low dose, results in high levels of virus in blood and severe depletion of peripheral blood $\mathrm{CD}_{4}^{+} \mathrm{T}$ cells. The observed $\mathrm{CD}_{4}^{+} \mathrm{T}$ cell depletion is consistent with the pathogenic nature of CXCR4-trophic HIV infection in humans.

After establishing the effect of LAI infection on peripheral blood $\mathrm{CD}^{+} \mathrm{T}$ cell levels, we evaluated its effect on $\mathrm{CD}^{+}$cell depletion in lymph nodes, spleen and in the human thymic organoid (HTO). LAI depleted $\mathrm{CD}^{+}{ }^{+} \mathrm{T}$ cells from lymph node and spleen at all doses (Figure 1C). The $\mathrm{CD}^{+}{ }^{+} \mathrm{CD}^{+}$double positive thymocytes were also efficiently depleted (Figure 1C). Interestingly, we noted that $\mathrm{CD}^{+} \mathrm{CD}^{-}$single positive cells in the thymus were relatively resistant to depletion with only the highest inoculum significantly decreasing the level of these cells (Figure 1C). After evaluating the dose-response relationship of LAI and establishing its pathogenic potential in BLT mice, we next investigated the role of Nef.

\section{Nef-defective LAI, LAINefdd}

To follow the course of infection by LAI with an irreversibly inactivated nef (LAINefdd) in humanized BLT mice LAINefdd was constructed (Figure 2). Two large deletions flanking the polypurine tract were introduced into nef. The double deletions reflect the long term convergent evolution of nef-defective virus in patients to lose all nef coding sequence except the PPT $[5,7,35,36]$. LAINefdd 

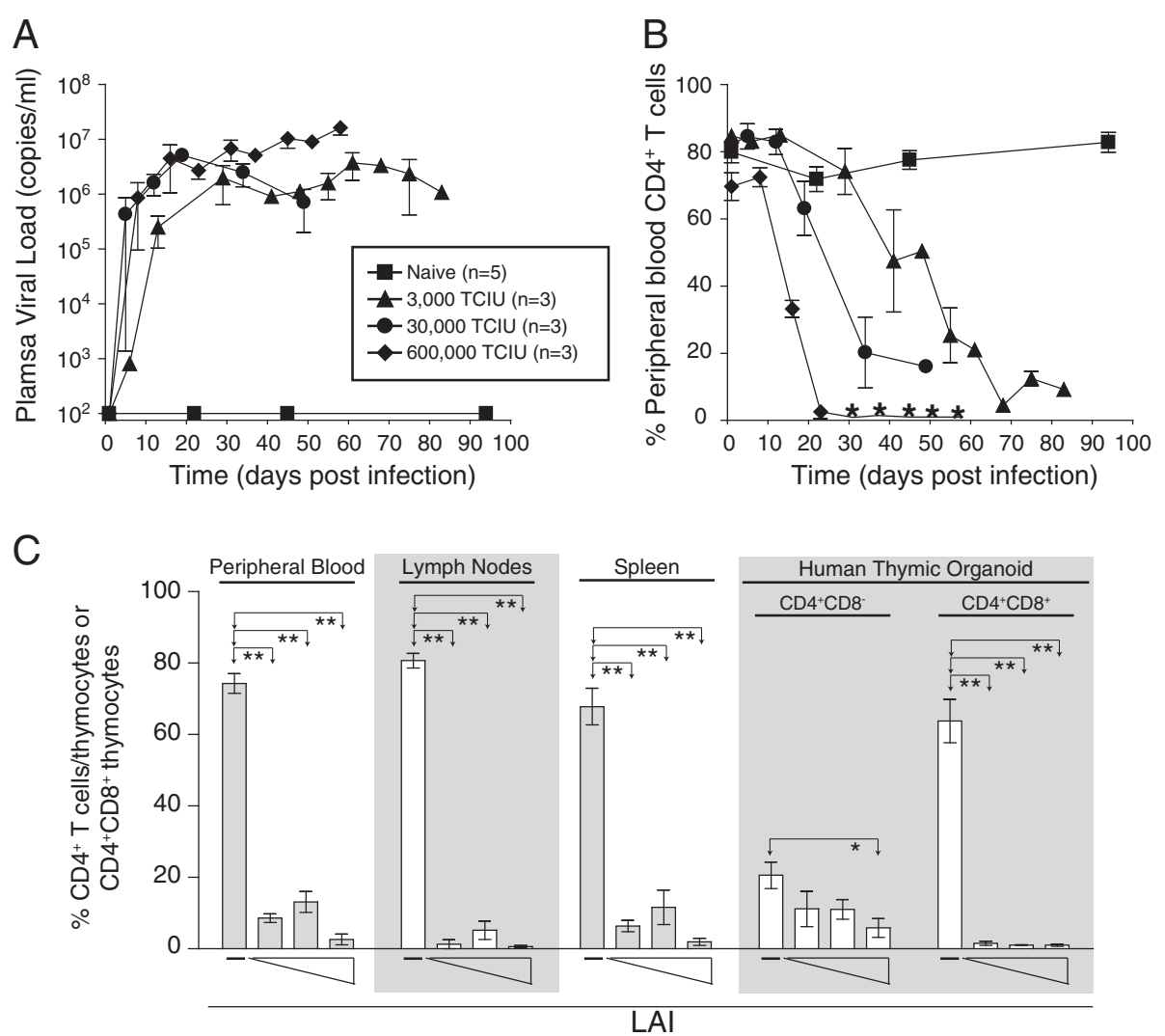

Figure 1 BLT humanized mice exhibited a profound loss of human CD4 ${ }^{+}$T cells/thymocytes following HIV-1 $1_{\text {LAI }}$ infection. (A-B) Three cohorts of BLT humanized mice were exposed intravenously to increasing doses of HIV-1 LAI (LAI). LAI inoculations included a low dose of 3000 TCIU (triangles), an intermediate dose of 30,000 TCIU (circles), and a high dose of 600,000 TCIU (diamonds). A fourth cohort consisted of naïve BLT humanized mice that were not exposed to virus (squares). Longitudinal analysis of plasma viral load revealed efficient viral replication in each of the three groups of LAl infected mice regardless of the inoculation dose, and no virus replication was observed in the naïve animals (A). In the absence of infection in naïve BLT humanized mice, the percentage of human CD4 ${ }^{+} \mathrm{T}$ cells in the peripheral blood remains constant. In contrast, $\mathrm{LAl}$ infected mice showed an inoculation dose dependent difference in the kinetics of CD4 ${ }^{+} \mathrm{T}$ cell loss. Asterisks represent the absence of detectable levels of peripheral blood human CD4 ${ }^{+} \mathrm{T}$ cells in the BLT humanized mice infected with 600,000 TCIU of LAl at the time point indicated (B). (C) Regardless of the inoculation dose, systemic loss of $C D 4^{+} T$ cells was observed in infected BLT humanized mice when compared to naive animals. Shown are the percentages of human $\mathrm{CD}^{+} \mathrm{T}$ cells present in peripheral blood, lymph nodes, and spleen, as well as the percentages of $\mathrm{CD}^{+} \mathrm{CD}^{-}$and $\mathrm{CD} 4^{+} \mathrm{CD} 8^{+}$thymocytes in the human thymic organoid. The percent of $\mathrm{CD} 4^{+} \mathrm{T}$ cells in peripheral blood or tissues

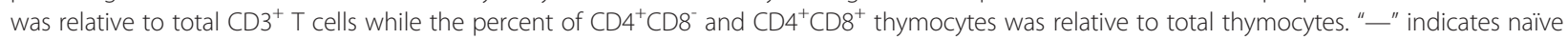
mice ( $n=5$ in PB, spleen and HTO or $n=4$ in LN). Triangles indicate the increasing doses: 3000 TCIU $(n=3), 30,000$ TCIU $(n=3), 600,000$ TCIU $(n=3)$. Unpaired two-tailed t tests were performed to compare the naïve mice to the mice in each LAl infection dose group within the same tissue. If no difference was detected, the comparison is unmarked (alpha $=0.05$ ). Comparisons yielding significant differences are represented by a line connecting the arrows above the respective bars $\left({ }^{*} p<0.05 ;{ }^{* *} p<0.01\right)$.

also models nef-defective virus from patients by maintaining conserved promoter elements in the $3^{\prime}$ end of U3 (Additional file 1: Figure S1). By a single round infection assay with TZM-bl cells, LAINefdd exhibited the expected reduction of virion infectivity $[37,38]$. The infectivity of LAINef $d d$ was not significantly different from that of LAINefXhoI with a non-deleted, frame-shifted nef (LAINefXhoI, see Additional file 2: Figure S2).

\section{Infection of BLT mice with a low dose of LAINefdd}

Four mice inoculated with 3000 TCIU of LAINefdd (0.56 ng $2^{\text {gag }}$ ) became systemically infected. The appearance of virus in peripheral blood was greatly delayed from the 7-14 days seen for wild-type LAIinfected mice (Figure 3A, LAI-1,-2 and -3) to 30-55 days for the four LAINef $d d$ infected mice $(p=0.014$, log rank test). These results demonstrate a generally reduced level of replication by the nef-deleted virus. However, in two of four mice (LAINefdd-2 and LAINefdd-4) viral loads did reach $10^{6}$ copies of viral RNA/ml of plasma demonstrating the in vivo fitness of nef-defective virus (Figure 3A). The other two mice (LAINefdd-1 and LAINefdd-3) had depressed viral replication with viral loads clearly under $10^{6}$ after sixty days. In contrast to the mice 


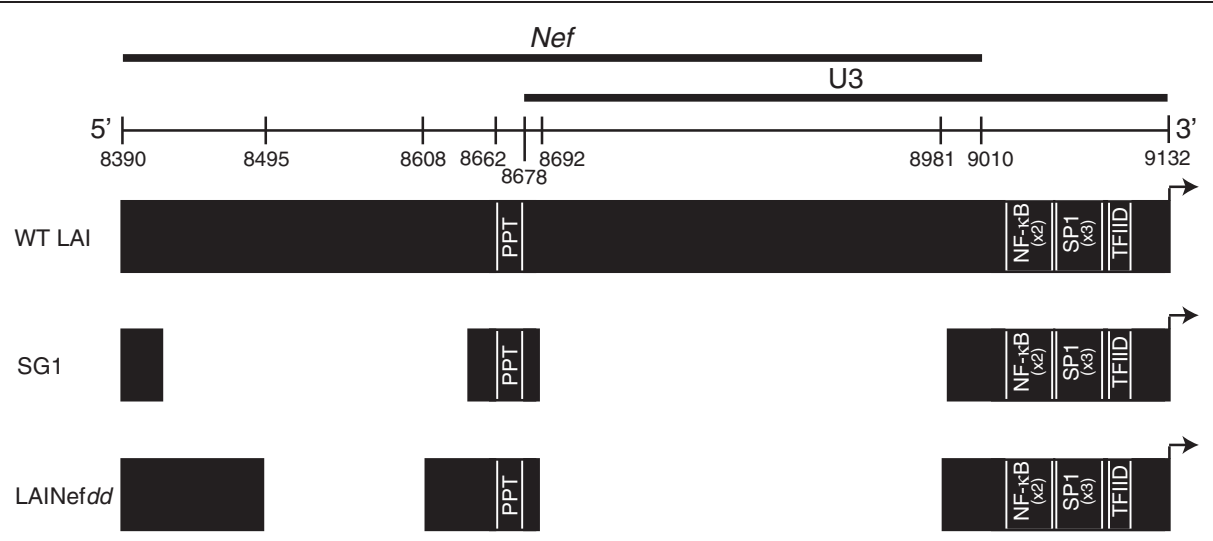

Figure 2 Schematic of WT LAI and LAINefdd. Three bars represent nef coding sequence and the U3 sequence for LAI, LAINefdd and patient SG1 clone 27 sequence [35]. SG1 clone 27 reflects the tendency of patients with defective nefs to lose all remaining coding sequence [5,7,35,36]. The coding sequence of WT type LAI nef (NCBI Accession, K02013) is presented in the top bar (nucleotides 8390-9010). PPT, polypurine tract is nucleotides 8662-8678. U3 consists of nucleotides 8678 to 9132. The core U3 promoter elements include two NF-kB binding sites, three SP1 sites and the TFIID binding site or TATA box. In the lower bar the $5^{\prime}$ deletion incorporated into LAINefdd is 114 nucleotides (8495-8608). Within the deletion, a four base insertion was added to create a frame shift (See Methods). The 3' gap in LAINefdd is a frame-shifting deletion of 290 bases (8692-8981). In the middle bar the deletions in SG1 isolate 27 are aligned with LAl. The gaps are not numbered for simplicity of presentation. The $5^{\prime}$ deletion in SG1 is 217 nucleotides and the $3^{\prime}$ deletion is 292 nucleotides.

infected with wild-type LAI, the LAINef $d d$ infected mice did not show significant depletion of their circulating $\mathrm{CD} 4^{+} \mathrm{T}$ cells (Figure 3B). Even the two mice whose viral loads reached $10^{6}$ copies $/ \mathrm{ml}$ maintained high levels of $\mathrm{CD} 4^{+} \mathrm{T}$ cells in peripheral blood (Figure 3B). Therefore, infection with a low dose of nef-deleted virus results in delayed replication and most strikingly a minimal capacity to induce peripheral $\mathrm{CD} 4^{+} \mathrm{T}$ cell depletion.

To further explore the impact of nef-defective HIV infection, $\mathrm{CD} 4^{+} \mathrm{T}$ cells in lymphocyte containing tissues were analyzed. As seen in Figure 3C, LAINefdd infection did not result in depletion of $\mathrm{CD} 4^{+} \mathrm{T}$ cells in lymph node (LN), spleen, bone marrow (BM), lung and liver reflecting what was observed in peripheral blood (Figure $3 \mathrm{~B}$ and $\mathrm{C}$ ). Consistent with the fact that at this low dose wild-type LAI did not induce a severe depletion of $\mathrm{CD}^{+} \mathrm{CD}^{-}$thymocytes, infection with the LAINefdd also did not result in $\mathrm{CD} 4^{+} \mathrm{CD} 8^{-}$thymocyte depletion (Compare Figure $1 \mathrm{C}$ and $3 \mathrm{C}$ ). However, a dramatic difference between LAI and LAINefdd infections was noted in the levels of $\mathrm{CD} 4^{+} \mathrm{CD} 8^{+}$thymocytes present in the implanted human thymus. Specifically, infection with wild-type virus resulted in a severe depletion of double positive thymocytes, but infection with the nef-deleted virus did not deplete these cells (Figure 3C). These data indicate that 3000 TCIU of LAINef $d d$ is sufficient to establish an infection in BLT humanized mice. However, consistent with Nef's role as an important replication and pathogenic factor LAINefdd was greatly reduced in its ability to initiate replication and to induce systemic $\mathrm{CD} 4^{+} \mathrm{T}$ cell and doublepositive thymocyte depletion.

\section{Infection of BLT mice with an intermediate dose of} LAINefdd

We next increased the inoculum of nef-defective HIV by 10 -fold $\left(30,000 \mathrm{TCIU}, 5.6 \mathrm{ng}\right.$ of $\left.\mathrm{p}^{\mathrm{gag}}\right)$ to assess the robustness of the nef-deleted phenotype. By two weeks, two mice infected with the LAINef $d d$ virus exhibited delayed replication and relatively low levels of virus in peripheral blood compared to LAI at the same dose (Figure 4A, LAINef $d d-5$ and LAINef $d d-7$ versus LAI-4, LAI-5, and LAI-6). These two LAINef $d d$-infected mice exhibited similar replication kinetics to LAINef $d d-1$ and LAINef $d d-3$ in Figure 3A. One mouse (LAINef $d d-6$ ) did not show detectable viral replication in the blood for 8 weeks, but ultimately reached about 1.5 million copies of viral RNA/ml (Figure 4A). A similar delay in viral replication has been reported for a humanized $\operatorname{Rag} 2^{-/-} \gamma_{\mathrm{c}}^{-/-}$ mouse infected with YU-2 [39]. It should be noted that despite active viral replication in these three mice receiving 30,000 LAINefdd TCIU, no CD4 ${ }^{+} \mathrm{T}$ cell decline was observed in peripheral blood (Figure 4B). LAI at 30,000 TCIU gave a dramatic depletion of $C D 4^{+} \mathrm{T}$ cells in blood by seven weeks (Figures $4 \mathrm{~A}$ and $\mathrm{B}$ ).

We then examined the levels of systemic $\mathrm{CD} 4^{+} \mathrm{T}$ cell depletion in the mice receiving this higher dose of virus. In the mice injected with LAI there was a dramatic depletion of $\mathrm{CD}^{+} \mathrm{T}$ cells in the lymph node, spleen, bone marrow, lung, liver and double positive thymocytes (Figure 4C). Importantly, CD4 ${ }^{+} \mathrm{T}$ cells were preserved in all the tissues analyzed from the mice infected with the nef-defective virus including the human thymic organoid (Figure 4C). These results demonstrate that, even with 10 -fold higher inoculums, nef-deleted LAI is still highly 

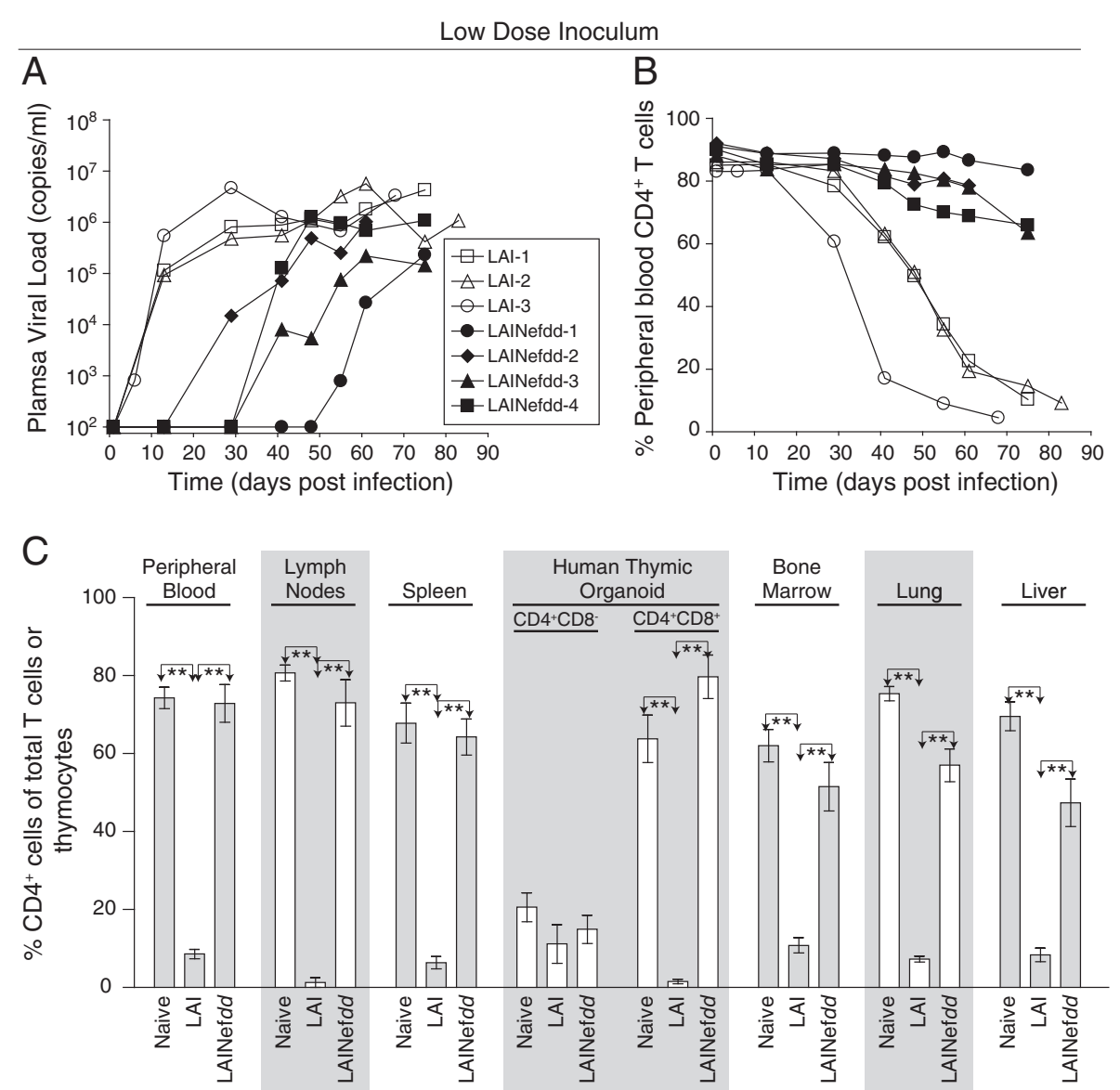

Figure 3 Analysis of BLT humanized mice inoculated with a low dose of nef(-) or wild-type LAI. (A) Each line depicts longitudinal plasma viral load data from individual BLT humanized mice infected with 3000 TCIU of LAINefdd (closed symbols) or LAI (open symbols). These data demonstrate delayed replication of LAINefdd relative to LAl following low dose inoculation. (B) Each line depicts the percentage of CD4 ${ }^{+} \mathrm{T}$ cells in peripheral blood over time where each animal's symbol is matched to the mice in (A). Mice infected with a low dose of LAINefdd showed minimal changes in $\mathrm{CD}^{+} \mathrm{T}$ cell percentages when compared to BLT humanized mice inoculated with an equal dose of LAI. (C) Naïve BLT humanized mice ( $n=5$ in PB, spleen and HTO or $n=4$ in LN, BM, lung and liver) and BLT humanized mice inoculated with 3000 TCIU of LAINefdd $(n=4)$ exhibited similar levels of $C D 4^{+}$cells while mice inoculated with the same dose of $L A I(n=3)$ exhibited a drastic reduction in these cells. Shown are the percentages of human $\mathrm{CD}^{+} \mathrm{T}$ cells present in peripheral blood, lymph nodes, spleen, bone marrow, lung and liver, as well as the percentages of $\mathrm{CD}^{+} \mathrm{CD}^{-}$and $\mathrm{CD} 4^{+} \mathrm{CD} 8^{+}$thymocytes in the human thymic organoid. The percent of $\mathrm{CD} 4^{+} \mathrm{T}$ cells in peripheral blood or tissues was relative to total $\mathrm{CD}^{+} \mathrm{T}$ cells while the percent of $\mathrm{CD} 4^{+} \mathrm{CD} 8^{-}$and $\mathrm{CD} 4^{+} \mathrm{CD} 8^{+}$thymocytes was relative to total thymocytes. One-way ANOVA with three Bonferroni multiple comparisons tests was performed to compare the results within each tissue. If no difference was detected, the comparison is unmarked (alpha $=0.05$ ). Comparisons yielding significant differences are represented by a line connecting the arrows above the respective bars $\left({ }^{* *} p<0.01\right)$.

attenuated in its ability to deplete T cells and thymocytes. However, the delay in viral replication observed in Figure $4 \mathrm{~A}$ appeared to be less dramatic at this higher dose for LAINef $d d-5$ and LAINef $d d-7$ than for LAINefdd infection at 3000 TCIU (Figure 3A). The extreme delay in LAINefdd-6 will be considered in the Discussion.

\section{Infection of BLT mice with a high dose of LAINefdd}

To further assess the phenotype of nef-defective virus we tested the possibility that an additional 20 -fold increase in viral inoculum would overwhelm the nefdeleted phenotype and result in pathogenic infection. A total of ten BLT mice (LAINef $d d$-8 through LAINef $d d$ 17) were infected at this supraphysiological dose $\left(6 \times 10^{5}\right.$ TCIU, $112 \mathrm{ng}$ of $\mathrm{p} 24^{\mathrm{gag}}$ ). Two different outcomes were observed. With seven of these infections, there were at most small drops in the levels of $\mathrm{CD} 4^{+} \mathrm{T}$ cells in peripheral blood; but with three mice substantial drops in CD4 $+\mathrm{T}$ cells were observed (Figure $5 \mathrm{~B}, 6 \mathrm{~B}$ and $6 \mathrm{D}$ ). As shown in Figure 5A and B, inoculation of BLT mice with $6 \times 10^{5} \mathrm{TCIU}$ of the wild-type LAI resulted in the rapid appearance of high levels of virus in peripheral blood, and depletion of peripheral blood $\mathrm{CD}^{+}$. $\mathrm{CD}^{+} \mathrm{T}$ cells were also depleted as seen in late stages of HIV-1 infection (not shown, $[40,41]$ ). Viral replication in two of the 

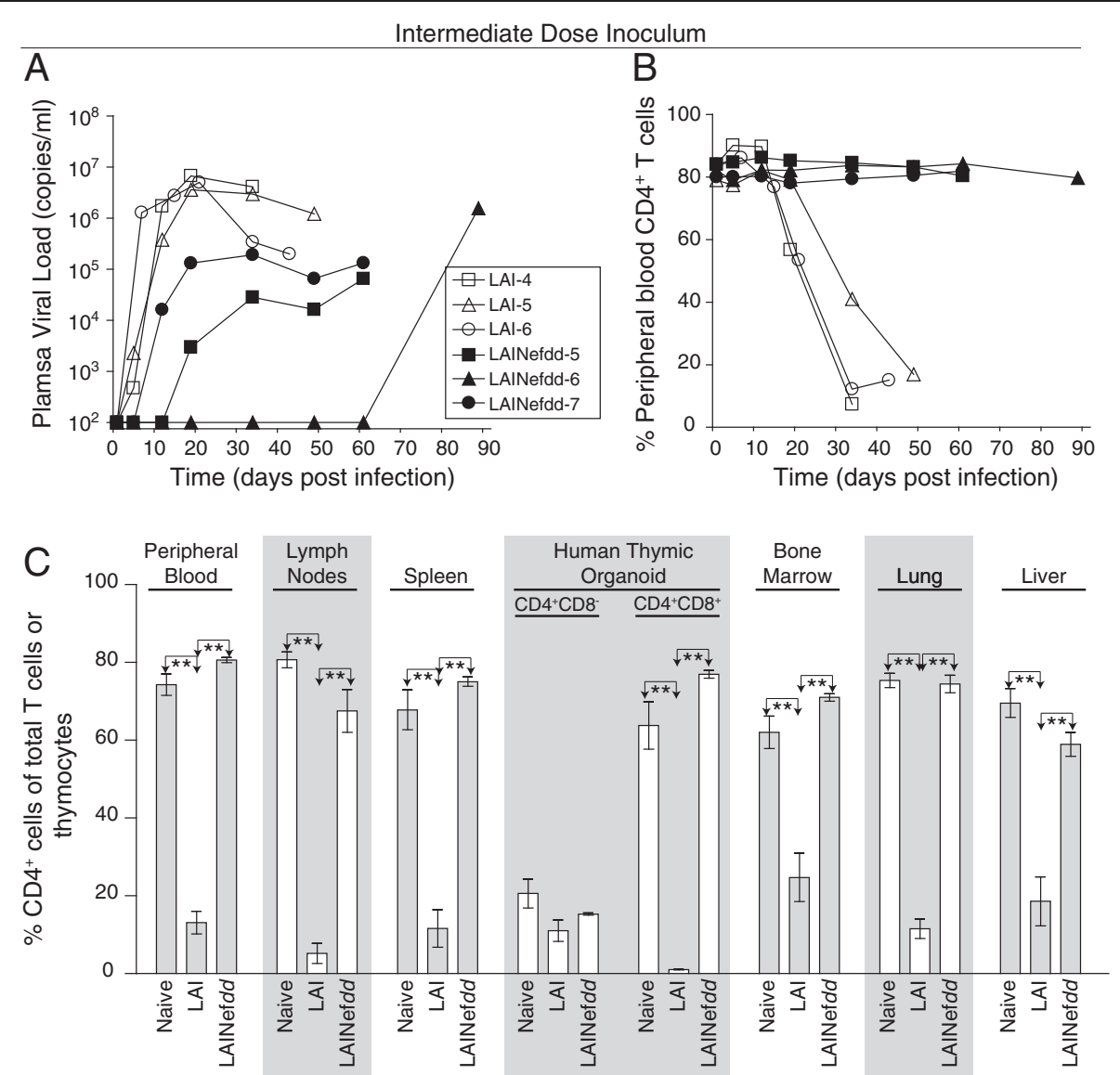

Figure 4 Analysis of BLT humanized mice inoculated with an intermediate dose of nef(-) or wild-type LAl. (A) Each line depicts longitudinal plasma viral load data from individual BLT humanized mice infected with 30,000 TCIU of LAINefdd (closed symbols) or LAI (open symbols). Two LAINefdd infected mice and all three LAl infected mice showed detectable viremia by three weeks post-exposure while one LAINefdd infected mouse exhibited delayed detection of viremia. (B) Each line depicts the percentage of CD4 ${ }^{+} T$ cells in peripheral blood over time where each animal's symbol is matched to the mice in (A). Mice infected with an intermediate dose of LAINefdd showed no changes in $\mathrm{CD}^{+} \mathrm{T}$ cell percentages whereas BLT humanized mice inoculated with an equal dose of LAl exhibited a decline of these cells. (C) Naive BLT humanized mice ( $n=5$ in PB, spleen and HTO or $n=4$ in LN, BM, lung and liver) and BLT humanized mice inoculated with 30,000 TCIU of LAINefdd $(n=3)$ exhibited similar levels of $C D 4^{+}$cells while mice inoculated with the same dose of $L A I(n=3)$ exhibited a drastic reduction in these cells. Shown are the percentages of human $\mathrm{CD}^{+} \mathrm{T}$ cells present in peripheral blood, lymph nodes, spleen, bone marrow, lung and liver, as well as the percentages of $\mathrm{CD}^{+} \mathrm{CD} 8$ and $\mathrm{CD}^{+} \mathrm{CD}^{+}$thymocytes in the human thymic organoid. The percent of $\mathrm{CD} 4^{+} \mathrm{T}$ cells in peripheral blood or tissues was relative to total $\mathrm{CD}^{+} \mathrm{T}$ cells while the percent of $\mathrm{CD} 4^{+} \mathrm{CD} 8^{-}$and $\mathrm{CD} 4^{+} \mathrm{CD} 8^{+}$thymocytes was relative to total thymocytes. One-way ANOVA with three Bonferroni multiple comparisons tests was performed to compare the results within each tissue. If no difference was detected, the comparison is unmarked (alpha $=0.05$ ). Comparisons yielding significant differences are represented by a line connecting the arrows above the respective bars $\left({ }^{* *} p<0.01\right)$.

LAINefdd mice yielded relatively high viral loads between $10^{5}$ and $10^{6}$ at two weeks (LAINef $d d-9$ and LAINefdd-11). In two other mice, plasma virus was less than 100,000 at two weeks (LAINefddd-8 and LAINefdd10). At these levels of LAINefdd replication, $\mathrm{CD} 4^{+} \mathrm{T}$ cell loss was essentially absent (Figure 5B).

At eight weeks post infection, we sacrificed the four LAINef $d d$ - and three LAI-infected mice to determine the levels of $\mathrm{CD}^{+} \mathrm{T}$ cells in tissues (Figure 5C). Systemically, infection with wild type LAI at this high dose resulted in near total depletion of $\mathrm{CD}^{+}{ }^{+} \mathrm{T}$ cells in all tissues analyzed and double-positive thymocytes as well.
Interestingly, single positive $\mathrm{CD}^{+}$thymocytes did not appear to be fully depleted by LAI (Figure $5 \mathrm{C}$ ). Mice infected with LAINefdd at this higher dose, maintained normal levels of $\mathrm{CD}^{+}{ }^{+} \mathrm{T}$ cells and double-positive thymocytes. These results demonstrate that over a 200-fold range in the dose of virus, Nef is necessary for rapid loss of $\mathrm{CD}^{+} \mathrm{T}$ cells and $\mathrm{CD} 4^{+} \mathrm{CD} 8^{+}$thymocytes. A role for Vpr, Env or possibly other HIV-1 proteins is not excluded, but all of these genes are functional in LAI and LAINef $d d$ [42-44]. A recent report found no impact of deleting vpu on $\mathrm{CD} 4^{+} \mathrm{T}$ cell depletion by $\mathrm{HIV}-1_{\mathrm{AD} 8+}$ in humanized mice [45]. 

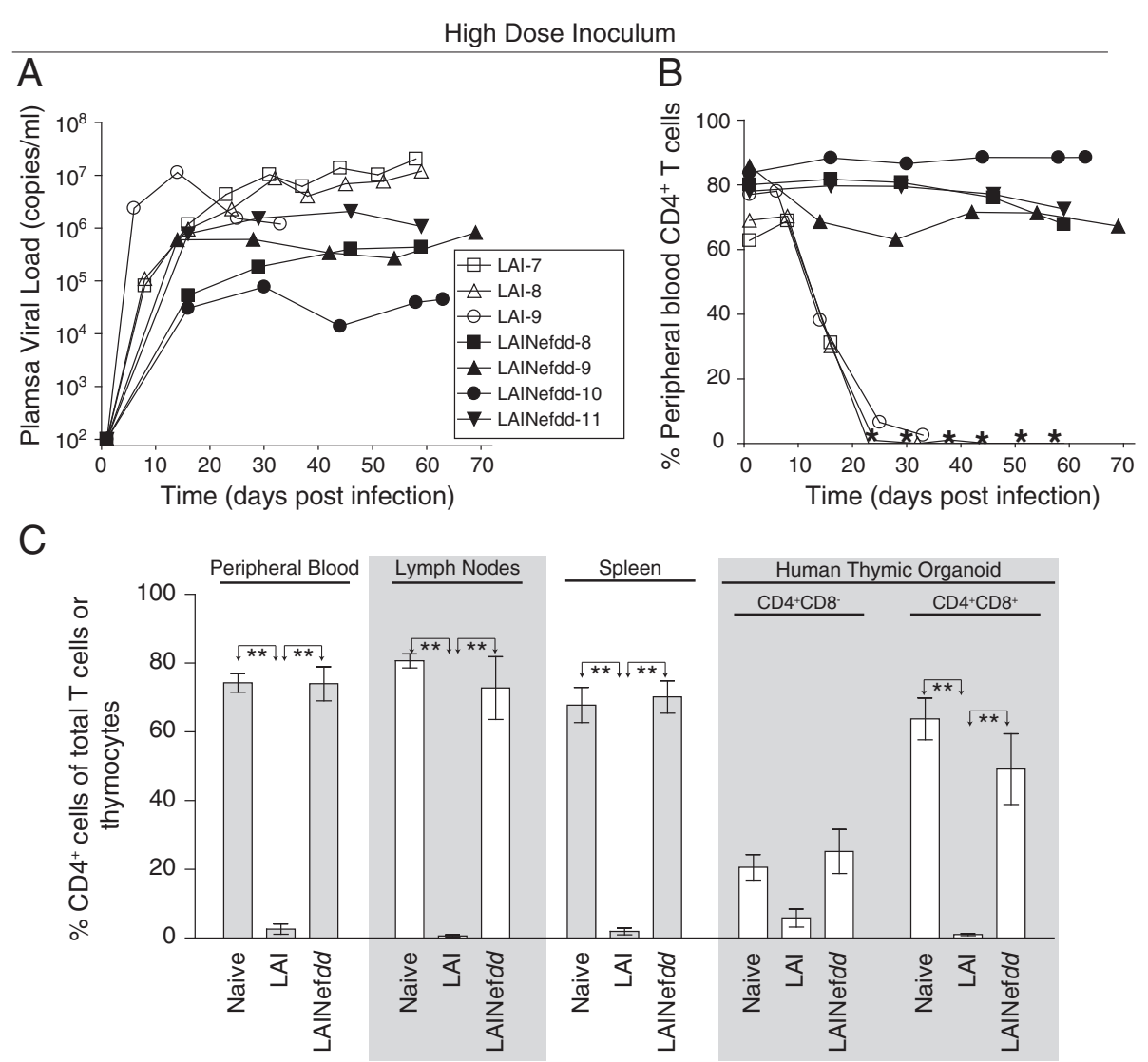

Figure 5 Analysis of BLT humanized mice inoculated with a high dose of nef(-) or wild-type LAI. (A) Each line depicts longitudinal plasma viral load data from individual BLT humanized mice infected with 600,000 TCIU of LAINefdd (closed symbols) or LAI (open symbols). All LAINefdd and LAI infected mice showed detectable viremia by two weeks post-exposure. (B) Each line depicts the percentage of CD4 ${ }^{+} \mathrm{T}$ cells in peripheral blood over time where each animal's symbol is matched to the mice in (A). Mice infected with a high dose of LAINefdd showed minimal changes in $\mathrm{CD}^{+} \mathrm{T}$ cell percentages. In contrast, BLT humanized mice inoculated with an equal dose of LAl exhibited a very rapid decline of CD4 ${ }^{+} T$ cells. Asterisks indicate that essentially all of these cells are eventually depleted in BLT humanized mice infected with 600,000 TCIU of LAI. (C) Naïve BLT mice $(n=5$ in PB, spleen and HTO or $n=4$ in LN) and BLT mice inoculated with 600,000 TCIU of LAINefdd $(n=4)$ exhibited similar levels of $C D 4^{+}$cells, while mice inoculated with the same dose of $\mathrm{LAl}(\mathrm{n}=3)$ exhibited a drastic reduction in these cells. Shown are the percentages of human $C D 4^{+} T$ cells present in peripheral blood, lymph nodes and spleen, as well as the percentages of $C D 4^{+} C D 8^{-}$and $C D 4^{+} C D 8$ ${ }^{+}$thymocytes in the human thymic organoid. The percent of $\mathrm{CD} 4^{+} \mathrm{T}$ cells in peripheral blood or tissues was relative to total $\mathrm{CD}^{+} \mathrm{T}$ cells while the percent of $\mathrm{CD}^{+} \mathrm{CD} 8^{-}$and $\mathrm{CD}^{+} \mathrm{CD}^{+}$thymocytes was relative to total thymocytes. One-way ANOVA with three Bonferroni multiple comparisons tests was performed to compare the results within each tissue. If no difference was detected, the comparison is unmarked (alpha $=0.05)$. Comparisons yielding significant differences are represented by a line connecting the arrows above the respective bars $\left({ }^{* *} p<0.01\right)$.

\section{Infection of BLT mice with a high dose of LAINefdd for an extended time course}

Our findings indicated that the dependence on Nef for replication was clearly evident at low and intermediate inoculums, but in some cases of the high initial inoculums of LAINefdd replication approached that of wildtype LAI. At high inoculum, the non-pathogenic phenotype of LAINefdd was still dramatic. We considered the possibility that longer courses of sustained infection may result in substantial $\mathrm{CD}^{+}{ }^{+} \mathrm{T}$ cell depletion. For this purpose, we followed six LAINef $d d$-infected mice infected with $6.0 \times 10^{5}$ TCIU for up to 170 days. As indicated above, three mice exposed to this high dose of LAINefdd exhibited reductions in $\mathrm{CD} 4^{+} \mathrm{T}$ cell levels in peripheral blood. These three mice had uncharacteristically high viral loads $\left(>10^{6}\right.$ copies $/ \mathrm{ml}$ of plasma) by two weeks (Figure 6A). Associated with this high viral load was a reduction of $\mathrm{CD}^{+} \mathrm{T}$ cells in the peripheral blood (Figure 6B). However, despite viral loads near that of wild-type virus, the time courses of $\mathrm{CD}^{+}{ }^{+} \mathrm{T}$ cell depletion were significantly delayed for an average of ten weeks for the nef-defective virus compared to less than three weeks for LAI (Figure 5B and 6B, Mantel-Cox Test, $p=0.025$ ). The reduced levels of $\mathrm{CD}^{+} \mathrm{T}$ cells in peripheral blood were mirrored by similar reductions in the lymph node, spleen, lung and liver but not in bone marrow of these animals (Figure 7 , see bars designated $6 A B)$. In contrast, the levels of thymocytes in these mice 

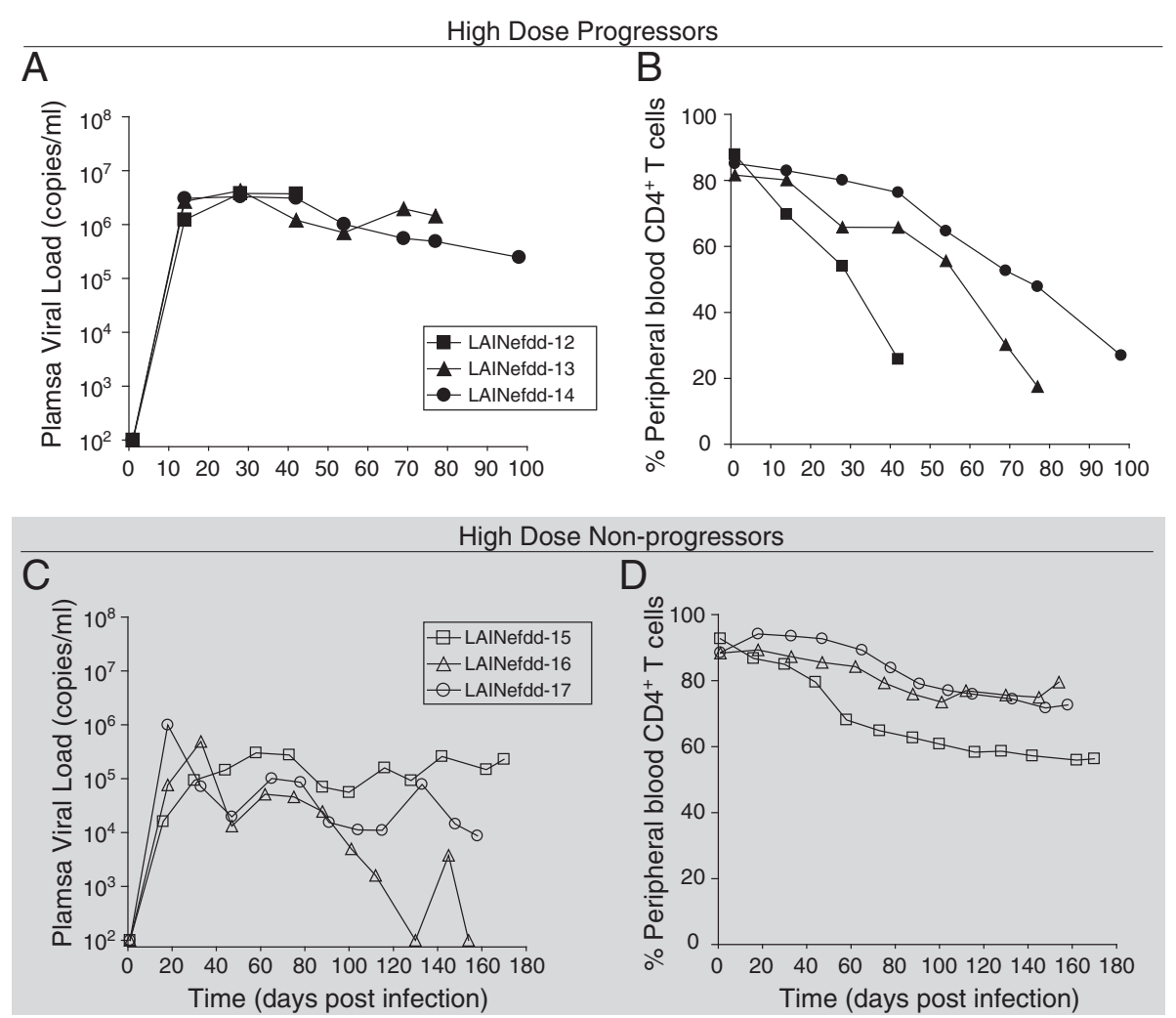

Figure 6 Distinct phenotypes in BLT humanized mice during long term infection with a high dose of LAINefdd. (A-B) Each line depicts longitudinal plasma viral load data (A), or the CD4 ${ }^{+} \mathrm{T}$ cell percentages (B) from individual BLT humanized mice infected with 600,000 TCIU of LAINefdd where each animal in (A) and (B) is symbol matched. Persistent viral replication and loss of CD4 $4^{+} \mathrm{T}$ cells in the peripheral blood were observed in each of these mice. (C-D) Each line depicts longitudinal plasma viral load data (C) or the $C D 4^{+} T$ cell percentages (D) from individual BLT humanized mice infected with 600,000 TCIU of LAINefdd where each animal in (C) and (D) is symbol matched. Viral replication and minimal loss of $\mathrm{CD}^{+} \mathrm{T}$ cells in the blood were observed in these mice over this extended experimental analysis.

were not significantly reduced (Figure $7, C D 4^{+} C D 8^{-}$, $\left.C D 4^{+} C D 8^{+}, 6 A B\right)$. The observations from these three mice suggest that even in the case of clear reductions $\mathrm{CD} 4^{+} \mathrm{T}$ cells, the nef-deleted virus was still much less cytotoxic than the wild-type virus to thymocytes.

We considered the possibility that LAINef $d d-12$, LAINef $d d-13$ and LAINef $d d-14$ exhibited T cell depletion because rearrangements of the remnants of nef coding sequence may generate a severely truncated nef open reading frame with some restoration of function. In Additional file 3: Figure S3, we have aligned the sequences for the nef regions obtained by RT-PCR from the terminal bleed of these mice. All three of the sequences are identical to the sequence of the input virus. Therefore, nef from these three mice remained non-functional.

In Figure $6 \mathrm{C}$ and $\mathrm{D}$, we present the final three mice that were infected with the highest dose of LAINefdd and were followed for 5-6 months post infection. The viral loads for these mice were maintained below $10^{6}$ copies LAINef $d d$ RNA/ml blood throughout the experiment (Figure 6C). For all of these mice, we observed only small drops in peripheral blood $\mathrm{CD}^{+} \mathrm{T}$ cells (Figure 6D). The results are in contrast to the complete loss of $\mathrm{CD}^{+} \mathrm{T}$ cells observed as early as twenty-one days in mice infected with 600,000 TCIU of LAI and further establish the significantly attenuated pathogenic phenotype of LAINef $d d$. Consistent with the results in Figure 6D for peripheral blood, the long term infections also did not result in $\mathrm{CD} 4^{+} \mathrm{T}$ cell depletion in any of the organs analyzed- lymph node, spleen, bone marrow, lung, and liver (Figure 7, 6CD). Single and double positive thymocytes were also clearly resistant to depletion by LAINef $d d$ infection (Figure 7, $6 C D$ ). In summary, the results indicate that the attenuated pathogenic phenotype of LAINefdd is not overwhelmed by a very high dose of virus.

The relationship between viral load, $\mathrm{T}$ cell activation, and the loss of peripheral blood $\mathrm{CD}^{+}{ }^{+} \mathrm{T}$ cells and thymocytes Recent studies of HIV-1 infection in BLT mice and patients have found evidence of elevated $\mathrm{CD} 38^{+} \mathrm{HLA}-\mathrm{DR}$ ${ }^{+} \mathrm{CD}^{+} \mathrm{T}$ cells in blood $[46,47]$. We also observed this effect with LAI infection. In naïve mice, $0.60 \% \pm 0.11 \%$, 


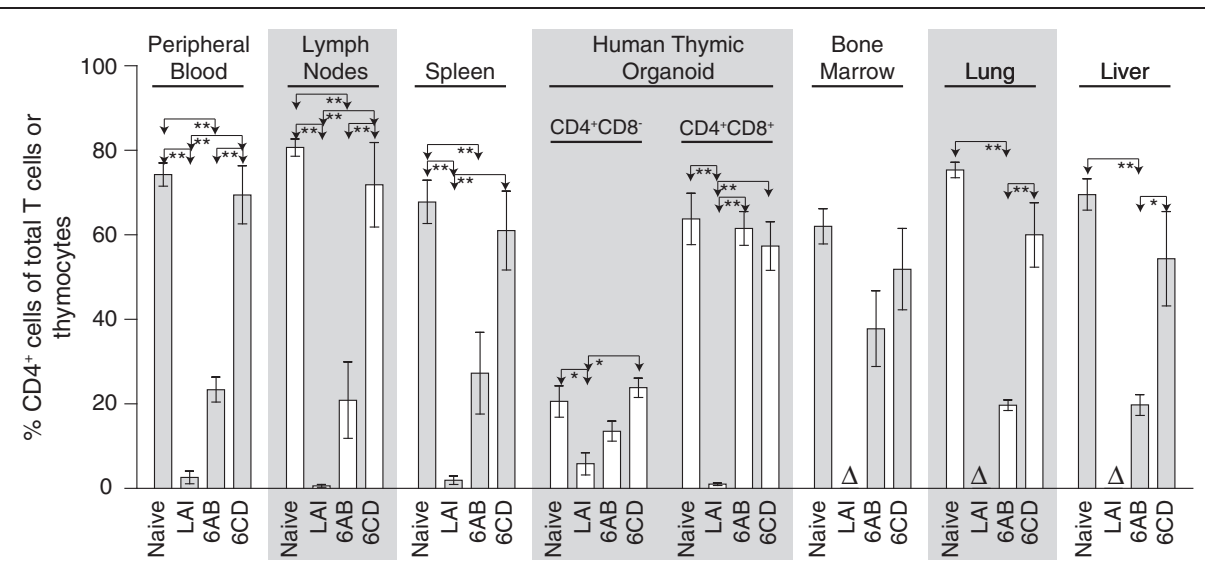

Figure 7 Impact of long-term infection with a high dose of LAINefdd in BLT humanized mice. The six BLT humanized mice infected with 600,000 TCIU of LAINefdd presented in Figure 6 were harvested for multiple tissue analyses at the last time points depicted in that figure. These mice are referred to here by the panels in which they appear in that figure $(6 \mathrm{AB}$ or $6 \mathrm{CD})$. Data from these mice are presented alongside data from naïve BLT humanized mice ( $n=5$ in PB, spleen and $H T O$ or $n=4$ in $L N$, BM, lung and liver) and BLT humanized mice inoculated with $600,000 \mathrm{TCIU}$ of $\mathrm{LAI}(n=3)$ to reveal that the $\mathrm{CD} 4^{+} \mathrm{T}$ cell loss patterns observed in the peripheral blood are mirrored by the multiple organ analyses performed. Shown are the percentages of human $\mathrm{CD}^{+} \mathrm{T}$ cells present in peripheral blood, lymph nodes, spleen, bone marrow, lung and liver, as well as the percentages of $\mathrm{CD}^{+} \mathrm{CD} 8^{-}$and $\mathrm{CD} 4^{+} \mathrm{CD} 8^{+}$thymocytes in the human thymic organoid. Delta symbols serve to indicate no data are available from bone marrow, lung or liver for LAI at 600,000 TCIU. The percent of CD4 ${ }^{+} \mathrm{T}$ cells in peripheral blood or tissues was relative to total $C D 3^{+} T$ cells while the percent of $C D 4^{+} C D 8^{-}$and $C D 4^{+} C D 8^{+}$thymocytes was relative to total thymocytes. One-way ANOVA with six Bonferroni multiple comparisons tests was performed to compare the results within each tissue. If no difference was detected, the comparison is unmarked (alpha $=0.05)$. Comparisons yielding significant differences are represented by a line connecting the arrows above the respective bars $\left({ }^{*} p<0.05 ;{ }^{* *} p<0.01\right)$.

$(\mathrm{n}=5)$ of $\mathrm{CD} 8^{+} \mathrm{T}$ cells in blood were CD38 ${ }^{+} \mathrm{HLA}-\mathrm{DR}^{+}$. For LAI and LAINefdd infected mice, there were $8.5 \% \pm 2.4 \%(\mathrm{n}=5)$ and $8.4 \% \pm 2.6 \%(\mathrm{n}=3)$ CD $38^{+} \mathrm{HLA}-$ $\mathrm{DR}^{+} \mathrm{CD}^{+} \mathrm{T}$ cells in blood, respectively, which is significantly higher than for naïve mice (Mann Whitney test, $p=0.012$ and $p=0.036$ ). LAI and LAINef $d d$ infected mice did not exhibit statistically different $\mathrm{CD}^{+} \mathrm{T}$ cell activation $(p=0.96)$. One explanation of these results is that relatively low levels of viral replication will induce $\mathrm{T}$ cell activation, but not $\mathrm{T}$ cell killing. In Table 1 , we present the peak values for all twenty-six infected mice. All nine mice infected with LAI had peak viral loads of greater than $3 \times 10^{6}$ copies of LAI RNA in blood with a mean \pm S.E.M. of $8.2 \times 10^{6} \pm 1.8 \times 10^{6}$ and a range of 3.6 to $20.4 \times 10^{6}$ copies of viral $\mathrm{RNA} / \mathrm{ml}$. Only three of seventeen LAINefdd mice had peak viral loads $>3 \times 10^{6}$ copies of viral RNA (LAINefdd-12, 13, and 14, Figure 6A), and all three exhibited $\mathrm{T}$ cell loss (Figure 6B). LAINefdd-2,-4,-6,-11 had peak viral loads of $1-2 \times 10^{6}$,but failed to deplete peripheral blood $\mathrm{T}$ cells (Table 1, Figure 3A, 4A and 5A). Therefore, peak viral loads $>3,000,000$ is associated with $\mathrm{T}$ cell depletion (Table 1, T cell Depletion). $\mathrm{CD} 4^{+} \mathrm{CD}^{+}$thymocyte depletion was not associated with peak viral load, but instead was determined by the presence or absence of Nef expression (Table $1, C D 4^{+} C D 8^{+}$Depletion).

A combined mechanism of $\mathrm{T}$ cell killing brought about by high viral replication plus reduced replacement of $\mathrm{T}$ cells by the thymus may account for the dramatic loss of
T cells we have observed with LAI infection. In the case of the three LAINef $d d$-infected mice that lost peripheral blood $\mathrm{T}$ cells, there was no loss of $\mathrm{CD} 4^{+} \mathrm{CD} 8^{+}$thymocytes which suggests that $\mathrm{T}$ cell replenishment may have been ongoing (Figure 7). This could account for the extended time course of $\mathrm{T}$ cell depletion for LAINefdd12, LAINef $d d-13$ and LAINef $d d-14$ relative to that observed for LAI infections at the high viral dose (Figures 5B and 6B).

HIV-1 infection results in depression of thymic output of $\mathrm{T}$ cells [48]. We have determined that deletion of the nef coding sequence prevents thymocyte loss by even a high dose of nef-defective virus. For T cell depletion, the cytoxcity of LAI appears to depend on reaching a threshold of replication not usually achieved by LAINef $d d$. Our results are consistent with Nef indirectly depleting $\mathrm{T}$ cells by elevating HIV-1 replication. However, $\mathrm{CD} 4^{+} \mathrm{CD} 8^{+}$thymocytes appear to be depleted by a different mechanism in which Nef is acting as a pathogenic factor.

\section{Discussion}

Recent reports have demonstrated the utility of the BLT humanized mouse model for investigating HIV-1 infection $[24,27,33,43,47]$. HIV-1 establishes a systemic infection with high viral loads that exhibits pathogenic properties by depleting human $\mathrm{CD} 4^{+} \mathrm{T}$ cells. Of particular interest to us was the extremely cytopathic phenotype of CXCR4-tropic viruses like HIV-1 $1_{\text {LAI }}$. This well 
Table 1 Relationship between Peak Viral Load, T cell depletion and CD4 ${ }^{+}$CD8 ${ }^{+}$Thymocyte Depletion ${ }^{\text {a }}$

\begin{tabular}{|c|c|c|c|c|}
\hline Mouse & Peak Viral Load ${ }^{\text {b }}$ (highest to lowest) & Inoculum (TCIU) ${ }^{c}$ & T cell Depletion $^{\mathrm{d}}$ & $\mathrm{CD}^{+} \mathrm{CD}^{+}{ }^{+}$Depletion $^{\mathrm{e}}$ \\
\hline$\overline{\mathrm{LAl}-7}$ & $2.04 \times 10^{7}$ & 600,000 & Yes & Yes \\
\hline LAl-8 & $1.19 \times 10^{7}$ & 600,000 & Yes & Yes \\
\hline LAI-9 & $1.13 \times 10^{7}$ & 600,000 & Yes & Yes \\
\hline LAl-4 & $6.70 \times 10^{6}$ & 30,000 & Yes & Yes \\
\hline LAl-2 & $5.63 \times 10^{6}$ & 3,000 & Yes & Yes \\
\hline LAI-6 & $4.99 \times 10^{6}$ & 30,000 & Yes & Yes \\
\hline LAl-3 & $4.64 \times 10^{6}$ & 3,000 & Yes & Yes \\
\hline LAI-1 & $4.25 \times 10^{6}$ & 3,000 & Yes & Yes \\
\hline LAINefdd-13 & $4.24 \times 10^{6}$ & 600,000 & Yes & No \\
\hline LAINefdd-12 & $3.77 \times 10^{6}$ & 600,000 & Yes & No \\
\hline LAl-5 & $3.59 \times 10^{6}$ & 30,000 & Yes & Yes \\
\hline LAINefdd-14 & $3.29 \times 10^{6}$ & 600,000 & Yes & No \\
\hline LAINefdd-11 & $2.07 \times 10^{6}$ & 600,000 & No & No \\
\hline LAINefdd-6 & $1.56 \times 10^{6}$ & 30,000 & No & No \\
\hline LAINefdd-4 & $1.25 \times 10^{6}$ & 3,000 & No & No \\
\hline LAINefdd-2 & $1.02 \times 10^{6}$ & 3,000 & No & No \\
\hline LAINefdd-17 & $9.93 \times 10^{5}$ & 600,000 & No & No \\
\hline LAINefdd-9 & $8.82 \times 10^{5}$ & 600,000 & No & No \\
\hline LAINefdd-16 & $4.90 \times 10^{5}$ & 600,000 & No & No \\
\hline LAINefdd-8 & $4.36 \times 10^{5}$ & 600,000 & No & No \\
\hline LAINefdd-15 & $3.00 \times 10^{5}$ & 600,000 & No & No \\
\hline LAINefdd-1 & $2.31 \times 10^{5}$ & 3,000 & No & No \\
\hline LAINefdd-3 & $2.20 \times 10^{5}$ & 3,000 & No & No \\
\hline LAINefdd-7 & $1.91 \times 10^{5}$ & 30,000 & No & No \\
\hline LAINefdd-10 & $7.73 \times 10^{4}$ & 600,000 & No & No \\
\hline LAINefdd-5 & $6.49 \times 10^{4}$ & 30,000 & No & No \\
\hline
\end{tabular}

a Summary of viral loads at peak viremia and depletion of T cell and double positive thymocytes.

${ }^{b}$ Copies viral RNA/ml plasma. LAI, $8.15 \times 10^{6} \pm 1.83 \times 10^{6}(n=9)$; LAINefdd, $1.24 \times 10^{6} \pm 0.32 \times 10^{6}(n=17)$.

c Dose of intravenous inoculum presented in tissue culture infectious doses (TCIU).

d "Yes," mice exhibiting reduction of peripheral blood $\mathrm{CD}^{+}$T cells below $50 \%$ of pre-infection level; viral load, $7.06 \times 10^{6} \pm 1.47 \times 10^{6}(\mathrm{n}=12$ ). "No," mice exhibiting peripheral blood $\mathrm{CD}^{+}$T cells not reduced below 50\%; viral load, $0.70 \times 106 \pm 0.16 \times 10^{6}(\mathrm{n}=14)$.

e "Yes," CD4+CD8 ${ }^{+}$thymocytes reduced below $10 \%$ total thymocytes. Viral loads for "Yes" and "No" same as LAI and LAINefdd, respectively ( ${ }^{\mathrm{b}}$ ).

characterized and fully functional virus replicates to high levels in BLT mice and rapidly depletes $\mathrm{CD}^{+} \mathrm{T}$ cells from blood and tissues [27]. The dramatic nature of this phenotype allowed us to investigate the role of Nef in two decisive phenotypes for the development of AIDS: maintenance of high levels of virus replication and depletion of $\mathrm{CD}^{+}{ }^{+} \mathrm{T}$ cells and thymocytes $[2,49]$. Our studies show that at low inoculums the $n e f$-deleted HIV-1 $1_{\text {LAI }}$ was doubly defective with delayed replication and a severely blunted capacity to deplete $\mathrm{CD} 4^{+} \mathrm{T}$ cells and thymocytes. Mice infected with 3000 TCIU of wild-type LAI exhibited a viral load of $10^{5}$ copies/ml of RNA 14 days post inoculation, but LAINefdd-infected mice only reached a viral load of $10^{5}$ copies $/ \mathrm{ml}$ at approximately 40, 40, 60, and 75 days post intravenous infection (Figure 3A). In addition, the low dose LAI-infected mice gave a 7-fold higher average peak viral load than the low dose LAINef $d d$-infected mice (Table 1). The pathogenic effect of Nef was also clearly demonstrated in Figure 3B, as LAI infection (3000 TCIU) resulted in an almost complete depletion of $\mathrm{CD}^{+} \mathrm{T}$ cells from peripheral blood, but LAINefdd infection resulted in at best a modest reduction in $\mathrm{CD}_{4}^{+} \mathrm{T}$ cells levels even after viral loads became elevated. Similar results were obtained at the ten-fold higher dose of 30,000 TCIU of LAI and LAINefdd (Figure 4). Thus, Nef is important, not only for efficient viral propagation, but also full pathogenicity in vivo.

At $600,000 \mathrm{TCIU}$ of LAINef $d d, \mathrm{CD}^{+}{ }^{+} \mathrm{T}$ cells were not depleted in seven of ten mice despite peak viral loads of $0.75 \times 10^{6} \pm 0.25 \times 10^{6}$ demonstrating the great importance of Nef for pathogenicity. However, three of ten mice 
infected with the highest dose of nef-deleted virus were observed to have a pathogenic phenotype (Figure 5B). These three mice exhibited efficient viral replication as reflected by high peak viral loads $\left(3.8 \times 10^{6} \pm 0.2 \times 10^{6}\right)$, but delayed reductions in $\mathrm{CD} 4^{+} \mathrm{T}$ cell levels. We attribute the loss of T cells in these mice to the high levels of replication of LAINefdd since no repair of the nef reading frame was observed. Repair of the defective nef was not expected, as all nef-defective HIV-1s from patients develop expanded deletions to include most of the nef coding sequence while sparing the polypurine tract $[4,7-9,36]$.

Precedent for a delayed pathogenic phenotype for nefdeleted HIV-1 has been reported for patients infected with nef-deleted virus that were followed for over 15 years (Table 2). Three of eight patients lost $\mathrm{CD}^{+}{ }^{+} \mathrm{T}$ cells to the extent that anti-retroviral therapy became necessary. The remaining five patients appear to be elite controllers (Table 2). That $63 \%$ of patients infected with nef-deleted HIV-1 that were documented for a sufficient length of time are elite controllers is in stark contrast to the less than $1 \%$ of elite controllers found in patients infected with nef-intact HIV-1 [1]. A simple interpretation is that the patient's immune system effectively controlled the nef-deleted HIV-1, but in three patients where the nef-defective virus was able to maintain replication, $\mathrm{CD}^{+}{ }^{+} \mathrm{T}$ cell levels began to decline after many years $[35,50]$. Unfortunately, thymic function in these three patients is not available.

Several Nef activities may be critical factors in the attenuation of LAI pathogenicity and replication that we observed. For example, we observed considerable delay

Table 2 Outcomes for patients infected with HIV-1nef(-) for longer than 15 years $^{a}$

\begin{tabular}{llll}
\hline Patient Identifier & Viral Load $^{\mathbf{b}}$ & Date Infected & ART $^{\text {C }}$ \\
\hline D36 & Low & 1980 & Yes, 1999 \\
C54 & Low & 1984 & No \\
C98 & Low & 1982 & Yes, 1999 \\
Patient 1 & BLD & Prior to 1983 & Yes, 1998 \\
Patient SG1 & BLD & 1985 & No \\
C49 & BLD & 1984 & No \\
C64 & BLD & 1983 & No \\
C135 & BLD & 1981 & No \\
\hline
\end{tabular}

${ }^{a}$ Patients reported to be infected by nef(-) HIV-1 for over fifteen years are presented with the appropriate identifier. D36, C54, C98, C49, C64, and C135 are from the Sydney Blood Bank Cohort $[5,50,51]$. Patient 1 was reported by Sullivan and co-workers [6,36,52]. Patient SG1 was reported by Benedetto and co-workers [9,35]. 'Viral Load represented as "Low" indicates copies of viral RNA were generally found to be less than 10,000 copies $/ \mathrm{ml}$ of peripheral blood but detectable. "BLD," indicates viral load generally below the level of detection. D36, C54 and C98 had viral loads that were consistently detectable [50,51]. Patient 1, Patient SG1, C49, C64, and C135 viral loads were not detectable $[6,35,50]$. The last four patients may have suppressed their HIV-1 infections by vigorous cytotoxic T cell responses [35,51]. C54 did not appear to be progressing to AIDS at the time of death in 2001 [50]. 'ART is antiretroviral therapy. in appearance of viral RNA in the blood for the lowest dose (Figure 3A). The loss of the enhancement of virion infectivity function could be significant early in infection to slow the rate of spread of the virus $[37,38]$. Subsequently, following the delay in replication, higher levels of virus could reduce the impact of this effect and result in some LAINef $d d$-infected mice presenting with viral loads over $10^{6}$. It is also important to determine the importance of another Nef activity, CD4 downregulation. Previous results from infections of SCID-hu thy/liv implants with Nefs mutated for residues (W57L58) critical for CD4 downregulation have given conflicting results. As a result, the importance of CD4 downregulation for replication and pathogenicity in vivo is unresolved $[21,22,53]$. The results presented here demonstrate that BLT mice have the potential to serve as an excellent model to address the roles of specific Nef functions described in vitro on Nef's phenotype in vivo.

We did not observe loss of $\mathrm{CD} 4^{+} \mathrm{CD}^{+}$thymocytes in LAINef $d d$ infections despite virtually complete depletion of this same cell population by LAI. Further, it appeared that $\mathrm{CD} 4^{+} \mathrm{CD} 8^{-}$thymocytes were resistant to killing by LAI. This in vivo result is similar to the ex vivo result reported by Choudhary et al. who reported a greater cytotoxic effect by CXCR4-trophic HIV-1 on $\mathrm{CD} 4^{+} \mathrm{CD} 8^{+}$ than on $\mathrm{CD}^{+} \mathrm{CD} 8^{-}$thymocytes [31]. This effect was attributed to $\mathrm{CD}^{+} \mathrm{CD}^{+}$, but not $\mathrm{CD} 4^{+} \mathrm{CD} 8^{-}$thymocytes, being primed for negative selection. Potentially consistent with the proposed susceptibility of $\mathrm{CD} 4{ }^{+} \mathrm{CD} 8$ + thymocytes to apoptosis, Nef has been reported to induce PD-1 and FasL [54,55].

In summary, we have demonstrated that LAI lacking Nef function is greatly attenuated for pathogenicity. However, under supraphysiological conditions of infection, this linkage is not absolute; and the defective virus retains some capacity to systemically reduce $\mathrm{CD}^{+} \mathrm{T}$ cells. HIV-1 gene products other than Nef that may be responsible for the residual pathogenicity of LAINefdd are Vpr or Env $[42,43,56]$. The availability of an in vivo system to study the roles of HIV-1 accessory genes in viral replication and depletion of $\mathrm{CD}^{+}{ }^{+} \mathrm{T}$ cells and thymocytes will help address currently unresolved questions. In particular, the mechanism of $\mathrm{Nef}$ induced killing of $\mathrm{CD}^{+} \mathrm{CD}^{+}$thymocytes needs to be explored in future studies as there is evidence of an important role for HIV-1 inhibition of $\mathrm{T}$ cell replenishment from the thymus in disease progression $[32,57]$.

\section{Conclusion}

We have investigated the infection of BLT humanized mice by wild-type and nef-defective HIV-1. With wild type virus, there is rapid and near total depletion of CD4 $+\mathrm{T}$ cells in blood and in multiple tissue compartments. $\mathrm{CD} 4^{+} \mathrm{CD}^{+}$thymocytes are also rapidly destroyed. With 
nef-defective virus, the course of infection is dramatically different. Despite the establishment of robust viral replication, there is rarely much loss of $\mathrm{CD} 4^{+} \mathrm{T}$ cells over the time frame that the wild-type virus systemically depletes these cells. With a high initial inoculum and an extended time course of infection, nef-defective virus may exhibit pathogenic properties. These observations are consistent with the conclusion that Nef is a replication factor and indirectly accelerates $\mathrm{T}$ cell killing by inducing high levels of viral replication. This mechanism does not apply to $\mathrm{CD} 4^{+} \mathrm{CD} 8^{+}$thymocytes, and our results suggest that Nef has a direct role in thymocyte killing. The effectiveness of CXCR4-trophic HIV-1 in depleting CD4 ${ }^{+}$ $\mathrm{T}$ cells may be enhanced by killing thymocytes and preventing thymic $\mathrm{T}$ cell replenishment.

\section{Methods}

\section{Preparation of humanized BLT mice}

Humanized BLT mice were prepared as previously described [24-27,34,58-60]. Briefly, thymus/liver implanted NOD/SCID or NOD/SCID IL- $2 \gamma^{-1-}$ mice (The Jackson Laboratories, Bar Harbor, ME) were transplanted with autologous human $\mathrm{CD} 34^{+}$cells isolated from fetal liver (Advanced Bioscience Resources, Alameda, CA). Human reconstitution in the peripheral blood of these mice was monitored periodically by flow cytometry (FACSCanto; BD Biosciences). Mice were maintained either at the Animal Resources Center, UT Southwestern Medical Center at Dallas (UTSWMC) or at the Division of Laboratory Animal Medicine, University of North Carolina at Chapel Hill (UNC-CH) in accordance with protocols approved by the UTSWMC or UNC-CH Institutional Animal Care and Use Committee. To ensure genetic diversity, seventeen different tissue donors were used to generate three groups of mice used for the experiments presented in this manuscript. Specifically, the percent engraftment for five naïve mice was $49.8 \% \pm 13.9 \%$ human $\mathrm{CD} 45^{+}$cells in blood from five of the donors, for the nine LAI-infected mice it was $40.3 \% \pm 8.0 \%$ human $\mathrm{CD} 45^{+}$cells in blood from seven of the donors, and for seventeen LAINefdd-infected mice it was $51.4 \% \pm 4.8 \%$ human CD $45^{+}$ cells in blood from nine of the donors. Engraftment did not significantly differ between the groups. Peak level of virus in blood did not correlate with human cell engraftment.

\section{Cell lines and culture conditions}

293T and TZM-bl cells were maintained in Dulbecco's modified Eagle's medium (DMEM; Cellgro, Herndon, VA) supplemented with $10 \%$ fetal bovine serum (FBS; Cellgro), $100 \mathrm{IU} / \mathrm{ml}$ of penicillin, $100 \mu \mathrm{g} / \mathrm{ml}$ streptomycin, and $2 \mathrm{mM}$ glutamine (Cellgro) in $10 \% \mathrm{CO}_{2}$ at $37^{\circ} \mathrm{C}$.

\section{Proviral clones}

The molecular clone, LAI (accession \# K02013), is described by Peden et al. [29]. pLAINefdd was made by first removing the internal XhoI and Acc65I fragment internal to nef, treating with Klenow and religating. This removes nucleotides 8495-8608, inclusive. The deleted LAI provirus was then cut at the reconstructed XhoI site, treated with Klenow and religated to introduce a frame shift (four base insertion) in addition to the deletion 114 bases. Second, nucleotides, 8692-8981, inclusive, were deleted by a site-directed mutagenesis strategy (Stratagene, USA). LAINefXhoI was constructed to be defective for nef by cutting the provirus with the single cutter Xhol, filling in with Klenow and religating. This leaves nef coding sequence intact but introduces a fourbase frameshift at nef codon 35. Lack of Nef expression by the mutants was confirmed by Western blot analysis. Our LAI construct is comparable to the double deleted NL4-3 construct of Gibbs et al. [61]. Converting NL4-3 numbers to homologous LAI numbers to compare the two constructs: the deletions were NL4-3/LAI (8428/ 8495 to $8650 / 8608$ for the $5^{\prime}$ deletion and $8718 / 8692$ to $8983 / 8981$ for the 3 ' deletion). This NL4-3 construct was used to produce virus for SCID-hu studies [22].

Virus production, exposure of BLT mice to HIV-1 LAI $_{\text {or nef- }}$

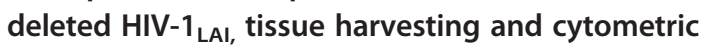
analyses

Stocks of LAI, LAINef $d d$ and LAIXhoI were prepared and titered as we previously described $[62,63]$. Briefly, proviral clones were transfected into 293T cells. Viral supernatant was collected 48 hours after transfection and diluted in Dulbecco's modified Eagle's medium (DMEM) supplemented with $10 \%$ fetal bovine serum, $100 \mathrm{IU}$ penicillin $/ \mathrm{ml}$, $100 \mu \mathrm{g} / \mathrm{ml}$ streptomycin, and $2 \mathrm{mM}$ glutamine. TZM-bl cells were infected in 12-well tissue culture plates with $0.4 \mathrm{ml}$ of virus containing medium for two hours. Then $1.0 \mathrm{ml}$ of supplemented DMEM was added, and the plates were incubated overnight. Virus containing medium was removed the next day and the incubation was continued for 24 hours. The cells were fixed and stained (40 hours after first exposure to virus). The titers of these viral stocks were determined in triplicate and at least two different titer determinations were performed in each batch of virus used for all the experiments described in this manuscript. p2 $4^{\mathrm{gag}}$ was determined for each prep of virus by ELISA.

Intravenous exposure of BLT mice with HIV-1 $1_{\text {LAI }}$ or HIV-1 $1_{\text {LAI }} d d$ was conducted via tail vein injection with 3000, 30,000 and $6 \times 10^{5}$ tissue culture infectious units (TCIU). Viral load in peripheral blood of infected mice was monitored longitudinally by quantitative real-time PCR using Taqman RNA to- $C_{\mathrm{T}}^{\mathrm{m}}$ 1-step kit from Applied Biosystems, USA $[34,64]$. The sequences of the forward and reverse primers and the Taqman probe for PCR 
were: 5' - CATGTTTTCAGCATTATCAGAAGGA- 3', 5'-TGCTTGATGTCCCCCCACT- $3{ }^{\prime}$, and $5^{\prime}$ - FAM CCACCCCACAAGATTTAAACACCATGCTAA- Q- 3' , respectively. $\mathrm{CD}_{4}^{+}$and $\mathrm{CD} 8^{+} \mathrm{T}$ cell levels were monitored by flow cytometric analysis.

Flow cytometric immunophenotyping was performed on peripheral blood samples longitudinally and mononuclear cells were isolated from tissues at harvest. Whole peripheral blood from humanized mice was analyzed according to the BD Biosciences Lyse/Wash protocol (Cat. No. 349202) as we have previously described $[24,26,27]$. Briefly, following antibody labeling of whole blood, red blood cells were lysed. The remaining cells were washed, fixed; and the sample was analyzed by flow cytometry. Tissue mononuclear cell isolations and immunophenotyping analyses were also performed according to published methods $[24,26,27]$. Flow cytometric gating for all samples was performed as follows: (step 1) forward and side scatter properities were utilized to set a live cell gate; (step2) live cells were then analyzed for expression of the human pan-leukocyte marker CD45; (step 3) human leukocytes were then analyzed for hCD3, hCD4 and/or hCD8 expression (step 4) in the case of $\mathrm{CD}^{+} \mathrm{T}$ cell activation analyses, peripheral blood human CD8+ T cells were analyzed for hCD38 and HLA-DR expression.

\section{Sequence analysis of plasma virions}

Viral RNA was extracted from $20 \mu \mathrm{l}$ of plasma from infected mice using the QIAamp Viral RNA Mini kit (Qiagen Sciences, USA). RNA was then reverse transcribed into cDNA, which was then subject to nested PCR. The outer primers for nef amplification are: $5^{\prime}$ AGCTTGCTCAATGCCACAGCC-3' and 5' $^{\prime}$ GCTGCATATAAGCAGCTGCTTTTTG-3'. And the inner primers are: 5'-TAGAGCTATTCGCCACATACC3' and 5'-GCTTGCTACAAGGGACTTTCCGC-3'. Gel purified PCR products were sequenced and the sequences aligned to $\mathrm{HIV}_{\mathrm{LAI}}$ sequences to determine if sequence changes had occurred.

\section{Statistics}

Log-rank (Mantel-Cox) tests (alpha level, 0.05) for initial viremia detection were performed using survival analyses in Prism version 4 (GraphPad). Unpaired two-tailed $t$ tests and one-way ANOVA were also performed in Prism version 4 (Graph Pad). All data were plotted as mean \pm S.E.M.

\section{Additional files}

Additional file 1 Figure S1. Alignment of LTR sequence from HIV-1 LAI and Sydney Blood Bank Cohort Patient D36. LAI LTR is the

nucleotide sequence of LAI U3, R and U5. U3 (black, red and green) and is numbered from the transcription start site to the $5^{\prime}$ end of $\mathrm{U} 3(-1$ to -454 ). $R$ (brown) is numbered from +1 to +97 and U5 (orange) is numbered from +98 to +181 . Above LAI LTR sequence is the translation of nef in three-letter amino acid code (black). The three colors for LAI U3 nucleotide sequence indicate- U3 general sequence (black), U3 sequence that is deleted in LAINefdd (red) and U3 sequence that represents transcription factor binding sites (green). D36 LTR is a nucleotide sequence from the donor in the Sydney Blood Bank Cohort (NCBI Accession DQ287276). The sequence is derived from a blood sample taken approximately 20 years post infection and is representative of nefs with large deletions on either side of the PPT [4,5]. D36 U3 sequence is presented in black and green. Black is general U3 sequence and green represents transcription factor binding sites. Dashes (black) represent D36 deleted sequence. Blue " $X$ 's" are for reported upstream transcription factor binding sites that are deleted in D36 LTR sequence. Asterisks indicate identical residues between LAl and D36 LTRs. A four base insertion in D36 LTR between A(-95) and C(-94) is shown below the asterisks. D36 R and D36 U5 are brown and orange, respectively. The sequence for D36 U5 is not complete. The conserved U3 core promoter $(-1$ to -122$)$ contains binding sites for multiple transcription factors. Estable et al. [65] determined that the conservation of the individual binding sites to be- TFIID (97\%), three intact SP1 (95\%) and two intact $\mathrm{NF}-\mathrm{KB}(85 \%)$. Just upstream of the core promoter the Ras response element binding factor 2, RBF-2 (63\%) and E26 transformation-specific domain protein, Ets (87\%) also are conserved. Note that all of these sites (green) are intact in LAINefdd and are present in the D36 LTR with the exception of Ets and possibly RBF-2. Binding sites for upstream stimulatory factor (USF), nuclear factor of activated T cells (NFAT) and chicken ovalbumin upstream promoter transcription factor (COUP-TF) are deleted in LAINefdd and D36 (blue). Deletion of the USF palindromic binding site, CACGTG, was reported to enhance viral replication [66]. However, CACGTG is only 15\% conserved and USF1 and USF2

overexpression activates HIV LTR independently of this site $[65,67]$. NFAT1 binding was reported to negatively impact HIV-1 replication though later studies found no effect and demonstrated that NFAT-1 binds to the tandem NF-KB sites $[66,68,69]$. COUP-TF binds at the gapped palindrome GGTCAN ${ }_{9}$ TGACC (LAI LTR nucleotides -348 to -320 ). This palindrome is found in LAl but is not conserved in subtype B nefs $[70,71]$.

Additional file 2 Figure S2. Infectivity of LAINefXhol and LAINefdd are similar. A single round infection assay was performed with the indicator cell line, TZM-bl, with LAI, LAINefXhol or LAINefdd. The mean infectivity of LAI (10,200 \pm 1270 TCIU per ng p2 $\left.4^{\text {gag }}\right)$ was set at $100 \%$. The infectivities of LAINefXhol (5260 \pm 630 TCIU per ng p24 $\left.{ }^{\text {gag }}\right)$ and LAINefdd (3400 \pm 570 per ng of p2 $4^{\text {gag }}$ ) were significantly less than LAl but not different from each other. Comparisons yielding significant differences are represented by a line connecting the arrows above the respective bars $\left.{ }^{* *} p<0.01\right)$.

Additional file 3 Figure S3. Alignment of nef sequences with LAI and LAINefdd sequences. nef was amplified by RT-PCR from blood of LAINefdd-12, LAINefdd-13 and LAINefdd-14 collected at tissue harvest (40, 78 and 90 days, respectively; Figure 6A and 6B). The amplified products were sequenced and aligned by Clustal X. Asterisks on the bottom line represent identical residues and dashes represent nucleotides deleted during the construction of the proviral clone of LAINefdd.

\section{Competing interests}

The authors declare that they have no competing interests.

\section{Acknowledgments}

This work was supported by grant Al33331 from the National Institute of Allergy and Infectious Diseases of the National Institutes of Health, USA and UNC CFAR P30 A1504410. Richard Watkins is supported by NIH Virology Training Grant 5T32A1007419 and Tomonori Nochi is supported by a Research Fellowship of the Japan Society for the Promotion of Science. We also acknowledge the advice we received from the UNC CFAR Statistics Core.

\section{Authors' contributions}

WZ, PWD, RLW, JFK, TN, and ML performed experiments and made Figures. PWD, JVG and JLF designed experiments and wrote the manuscript. All authors read and approved the final manuscript. 
Received: 18 March 2012 Accepted: 28 May 2012

Published: 28 May 2012

\section{References}

1. Okulicz JF, Marconi VC, Landrum ML, Wegner S, Weintrob A, Ganesan A, Hale B, Crum-Cianflone N, Delmar J, Barthel V, et al: Clinical outcomes of elite controllers, viremic controllers, and long-term nonprogressors in the US Department of Defense HIV natural history study. J Infect Dis 2009, 200:1714-1723.

2. Stevenson M: HIV-1 pathogenesis. Nat Med 2003, 9:853-860.

3. Braibant M, Xie J, Samri A, Agut H, Autran B, Barin F: Disease progression due to dual infection in an HLA-B57-positive asymptomatic long-term nonprogressor infected with a nef-defective HIV-1 strain. Virology 2010, 405:81-92.

4. Churchill MJ, Rhodes DI, Learmont JC, Sullivan JS, Wesselingh SL, Cooke IR, Deacon NJ, Gorry PR: Longitudinal analysis of human immunodeficiency virus type 1 nef/long terminal repeat sequences in a cohort of long-term survivors infected from a single source. J Virol 2006, 80:1047-1052.

5. Gorry PR, McPhee DA, Verity E, Dyer WB, Wesselingh SL, Learmont J, Sullivan JS, Roche M, Zaunders JJ, Gabuzda D, et al: Pathogenicity and immunogenicity of attenuated, nef-deleted HIV-1 strains in vivo. Retrovirology 2007, 4:66.

6. Greenough TC, Sullivan JL, Desrosiers RC: Declining CD4 T-cell counts in a person infected with nef-deleted HIV-1. N Engl J Med 1999, 340:236-237.

7. Kondo M, Shima T, Nishizawa M, Sudo K, Iwamuro S, Okabe T, Takebe Y, Imai M: Identification of attenuated variants of HIV-1 circulating recombinant form 01_AE that are associated with slow disease progression due to gross genetic alterations in the nef/long terminal repeat sequences. J Infect Dis 2005, 192:56-61.

8. Rhodes DI, Ashton L, Solomon A, Carr A, Cooper D, Kaldor J, Deacon N: Characterization of three nef-defective human immunodeficiency virus type 1 strains associated with long-term nonprogression. Australian Long-Term Nonprogressor Study Group. J Virol 2000, 74:10581-10588.

9. Salvi R, Garbuglia AR, Di Caro A, Pulciani S, Montella F, Benedetto A: Grossly defective nef gene sequences in a human immunodeficiency virus type 1-seropositive long-term nonprogressor. J Virol 1998, 72:3646-3657.

10. Hofmann-Lehmann R, Vlasak J, Williams AL, Chenine AL, McClure HM, Anderson DC, O'Neil S, Ruprecht RM: Live attenuated, nef-deleted SIV is pathogenic in most adult macaques after prolonged observation. AIDS 2003, 17:157-166

11. Kestler HW 3rd, Ringler DJ, Mori K, Panicali DL, Sehgal PK, Daniel MD, Desrosiers RC: Importance of the nef gene for maintenance of high virus loads and for development of AIDS. Cell 1991, 65:651-662.

12. Hanna Z, Kay DG, Rebai N, Guimond A, Jothy S, Jolicoeur P: Nef harbors a major determinant of pathogenicity for an AIDS-like disease induced by HIV-1 in transgenic mice. Cell 1998, 95:163-175.

13. Rahim MM, Chrobak P, Hu C, Hanna Z, Jolicoeur P: Adult AIDS-like disease in a novel inducible human immunodeficiency virus type $1 \mathrm{Nef}$ transgenic mouse model: CD4+ T-cell activation is Nef dependent and can occur in the absence of lymphophenia. J Virol 2009, 83:11830-11846.

14. Skowronski J, Parks D, Mariani R: Altered T cell activation and development in transgenic mice expressing the HIV-1 nef gene. EMBO $\mathrm{J}$ 1993, 12:703-713.

15. Glushakova S, Grivel JC, Suryanarayana K, Meylan P, Lifson JD, Desrosiers R, Margolis L: Nef enhances human immunodeficiency virus replication and responsiveness to interleukin-2 in human lymphoid tissue ex vivo. $J$ Virol 1999, 73:3968-3974.

16. Glushakova S, Munch J, Carl S, Greenough TC, Sullivan JL, Margolis L, Kirchhoff F: CD4 down-modulation by human immunodeficiency virus type 1 Nef correlates with the efficiency of viral replication and with CD4(+) T-cell depletion in human lymphoid tissue ex vivo. J Virol 2001, 75:10113-10117.

17. Homann S, Tibroni N, Baumann I, Sertel S, Keppler OT, Fackler OT: Determinants in HIV-1 Nef for enhancement of virus replication and depletion of CD4+ T lymphocytes in human lymphoid tissue ex vivo. Retrovirology 2009, 6:6.

18. Munch J, Rajan D, Schindler M, Specht A, Rucker E, Novembre FJ, Nerrienet E, Muller-Trutwin MC, Peeters M, Hahn BH, Kirchhoff F: Nef-mediated enhancement of virion infectivity and stimulation of viral replication are fundamental properties of primate lentiviruses. J Virol 2007, 81:13852-13864.
19. Duus KM, Miller ED, Smith JA, Kovalev Gl, Su L: Separation of human immunodeficiency virus type 1 replication from nef-mediated pathogenesis in the human thymus. J Virol 2001, 75:3916-3924.

20. Jamieson BD, Aldrovandi GM, Planelles V, Jowett JB, Gao L, Bloch LM, Chen IS, Zack JA: Requirement of human immunodeficiency virus type 1 nef for in vivo replication and pathogenicity. J Virol 1994, 68:3478-3485.

21. Stoddart CA, Geleziunas R, Ferrell S, Linquist-Stepps V, Moreno ME, Bare C, Xu W, Yonemoto W, Bresnahan PA, McCune JM, Greene WC: Human immunodeficiency virus type 1 Nef-mediated downregulation of CD4 correlates with Nef enhancement of viral pathogenesis. J Virol 2003, 77:2124-2133.

22. Aldrovandi GM, Gao L, Bristol G, Zack JA: Regions of human immunodeficiency virus type 1 nef required for function in vivo. $J$ Virol 1998, 72:7032-7039.

23. Aldrovandi GM, Zack JA: Replication and pathogenicity of human immunodeficiency virus type 1 accessory gene mutants in SCID-hu mice. J Virol 1996, 70:1505-1511.

24. Denton PW, Estes JD, Sun Z, Othieno FA, Wei BL, Wege AK, Powell DA, Payne D, Haase AT, Garcia JV: Antiretroviral pre-exposure prophylaxis prevents vaginal transmission of HIV-1 in humanized BLT mice. PLoS Med 2008, 5:e16.

25. Denton PW, Krisko JF, Powell DA, Mathias M, Kwak YT, Martinez-Torres F, Zou W, Payne DA, Estes JD, Garcia JV: Systemic administration of antiretrovirals prior to exposure prevents rectal and intravenous HIV-1 transmission in humanized BLT mice. PLoS One 2010, 5:e8829.

26. Melkus MW, Estes JD, Padgett-Thomas A, Gatlin J, Denton PW, Othieno FA, Wege AK, Haase AT, Garcia JV: Humanized mice mount specific adaptive and innate immune responses to EBV and TSST-1. Nat Med 2006, 12:1316-1322.

27. Sun Z, Denton PW, Estes JD, Othieno FA, Wei BL, Wege AK, Melkus MW, Padgett-Thomas A, Zupancic M, Haase AT, Garcia JV: Intrarectal transmission, systemic infection, and CD4+ T cell depletion in humanized mice infected with HIV-1. J Exp Med 2007, 204:705-714

28. Denton PW, Garcia JV: Humanized mouse models of HIV infection. AIDS Rev 2011, 13:135-148.

29. Peden K, Emerman M, Montagnier L: Changes in growth properties on passage in tissue culture of viruses derived from infectious molecular clones of HIV-1LAI, HIV-1MAL, and HIV-1ELI. Virology 1991, 185:661-672.

30. Schweighardt B, Roy AM, Meiklejohn DA, Grace EJ 2nd, Moretto WJ, Heymann JJ, Nixon DF: R5 human immunodeficiency virus type 1 (HIV-1) replicates more efficiently in primary CD4+ T-cell cultures than X4 HIV-1. J Virol 2004, 78:9164-9173.

31. Choudhary SK, Walker RM, Powell DM, Planelles V, Walsh C, Camerini D: CXCR4 tropic human immunodeficiency virus type 1 induces an apoptotic cascade in immature infected thymocytes that resembles thymocyte negative selection. Virology 2006, 352:268-284.

32. Dion ML, Bordi R, Zeidan J, Asaad R, Boulassel MR, Routy JP, Lederman MM, Sekaly RP, Cheynier R: Slow disease progression and robust therapymediated CD4+ T-cell recovery are associated with efficient thymopoiesis during HIV-1 infection. Blood 2007, 109:2912-2920.

33. Brainard DM, Seung E, Frahm N, Cariappa A, Bailey CC, Hart WK, Shin HS, Brooks SF, Knight HL, Eichbaum Q, et al: Induction of robust cellular and humoral virus-specific adaptive immune responses in human immunodeficiency virus-infected humanized BLT mice. J Virol 2009, 83:7305-7321.

34. Denton PW, Othieno F, Martinez-Torres F, Zou W, Krisko JF, Fleming E, Zein S, Powell DA, Wahl A, Kwak YT, et al: One percent tenofovir applied topically to humanized BLT mice and used according to the CAPRISA 004 experimental design demonstrates partial protection from vaginal HIV infection, validating the BLT model for evaluation of new microbicide candidates. J Virol 2011, 85:7582-7593.

35. Calugi G, Montella F, Favalli C, Benedetto A: Entire genome of a strain of human immunodeficiency virus type 1 with a deletion of nef that was recovered 20 years after primary infection: large pool of proviruses with deletions of env. J Virol 2006, 80:11892-11896.

36. Kirchhoff F, Greenough TC, Brettler DB, Sullivan JL, Desrosiers RC: Brief report: absence of intact nef sequences in a long-term survivor with nonprogressive HIV-1 infection. N Engl J Med 1995, 332:228-232.

37. Miller MD, Warmerdam MT, Gaston I, Greene WC, Feinberg MB: The human immunodeficiency virus-1 nef gene product: a positive factor for vira infection and replication in primary lymphocytes and macrophages. $J$ Exp Med 1994, 179:101-113. 
38. Pizzato M, Helander A, Popova E, Calistri A, Zamborlini A, Palu G, Gottlinger HG: Dynamin 2 is required for the enhancement of HIV-1 infectivity by Nef. Proc Natl Acad Sci U S A 2007, 104:6812-6817.

39. Baenziger S, Tussiwand R, Schlaepfer E, Mazzucchelli L, Heikenwalder M, Kurrer MO, Behnke S, Frey J, Oxenius A, Joller H, et al: Disseminated and sustained HIV infection in CD34+ cord blood cell-transplanted Rag2 -/-gamma c-/- mice. Proc Natl Acad Sci U S A 2006, 103:15951-15956.

40. Douek DC, Betts MR, Hill BJ, Little SJ, Lempicki R, Metcalf JA, Casazza J, Yoder C, Adelsberger JW, Stevens RA, et al: Evidence for increased T cell turnover and decreased thymic output in HIV infection. J Immuno/ 2001 167:6663-6668.

41. Douek DC, McFarland RD, Keiser PH, Gage EA, Massey JM, Haynes BF, Polis MA, Haase AT, Feinberg MB, Sullivan $J L$, et al: Changes in thymic function with age and during the treatment of HIV infection. Nature 1998, 396:690-695.

42. Cummins NW, Badley AD: Mechanisms of HIV-associated lymphocyte apoptosis: 2010. Cell Death Dis 2010, 1:e99.

43. Garg H, Joshi A, Ye C, Shankar P, Manjunath N: Single amino acid change in gp41 region of HIV-1 alters bystander apoptosis and CD4 decline in humanized mice. Virol J 2011, 8:34.

44. Zhao RY, Li G, Bukrinsky MI: Vpr-host interactions during HIV-1 viral life cycle. J Neuroimmune Pharmacol 2011, 6:216-229.

45. Sato K, Misawa N, Fukuhara M, Iwami S, An DS, Ito M, Koyanagi Y: Vpu augments the initial burst phase of HIV-1 propagation and downregulates BST2 and CD4 in humanized mice. J Virol 2012, 86:5000-5013

46. Hunt PW, Landay AL, Sinclair E, Martinson JA, Hatano H, Emu B, Norris PJ, Busch MP, Martin JN, Brooks C, et al: A low T regulatory cell response may contribute to both viral control and generalized immune activation in HIV controllers. PLoS One 2011, 6:e15924.

47. Long BR, Stoddart CA: Alpha interferon and HIV Infection Cause Activation of Human T Cells in NSG-BLT Mice. J Virol 2012, 86:3327-3336.

48. Dion ML, Poulin JF, Bordi R, Sylvestre M, Corsini R, Kettaf N, Dalloul A, Boulassel MR, Debre P, Routy JP, et al: HIV infection rapidly induces and maintains a substantial suppression of thymocyte proliferation. Immunity 2004, 21:757-768

49. Gaulton GN, Scobie JV, Rosenzweig M: HIV-1 and the thymus. AIDS 1997, 11:403-414.

50. Dyer WB, Zaunders JJ, Yuan FF, Wang B, Learmont JC, Geczy AF, Saksena NK, McPhee DA, Gorry PR, Sullivan JS: Mechanisms of HIV nonprogression; robust and sustained CD4+ T-cell proliferative responses to p24 antigen correlate with control of viraemia and lack of disease progression after long-term transfusion-acquired HIV-1 infection. Retrovirology 2008, 5:112.

51. Zaunders J, Dyer WB, Churchill M: The Sydney Blood Bank Cohort: implications for viral fitness as a cause of elite control. Curr Opin HIV AIDS 2011, 6:151-156.

52. Greenough TC, Brettler DB, Kirchhoff F, Alexander L, Desrosiers RC, O'Brien SJ, Somasundaran M, Luzuriaga K, Sullivan JL: Long-term nonprogressive infection with human immunodeficiency virus type 1 in a hemophilia cohort. J Infect Dis 1999, 180:1790-1802.

53. Mangasarian A, Piguet V, Wang JK, Chen YL, Trono D: Nef-induced CD4 and major histocompatibility complex class I (MHC-I) down-regulation are governed by distinct determinants: $\mathrm{N}$-terminal alpha helix and proline repeat of Nef selectively regulate MHC-I trafficking. J Virol 1999, 73:1964-1973.

54. Muthumani K, Choo AY, Hwang DS, Premkumar A, Dayes NS, Harris C, Green DR, Wadsworth SA, Siekierka JJ, Weiner DB: HIV-1 Nef-induced FasL induction and bystander killing requires p38 MAPK activation. Blood 2005, 106:2059-2068.

55. Muthumani K, Choo AY, Shedlock DJ, Laddy DJ, Sundaram SG, Hirao L, Wu L, Thieu KP, Chung CW, Lankaraman KM, et al: Human immunodeficiency virus type 1 Nef induces programmed death 1 expression through a p38 mitogen-activated protein kinase-dependent mechanism. J Virol 2008, 82:11536-11544

56. Lu TC, He JC, Wang ZH, Feng X, Fukumi-Tominaga T, Chen N, Xu J, lyengar R, Klotman PE: HIV-1 Nef disrupts the podocyte actin cytoskeleton by interacting with diaphanous interacting protein. J Biol Chem 2008 , 283:8173-8182.

57. Franco JM, Rubio A, Martinez-Moya M, Leal M, Merchante E, SanchezQuijano A, Lissen E: T-cell repopulation and thymic volume in HIV-1- infected adult patients after highly active antiretroviral therapy. Blood 2002, 99:3702-3706.

58. Kim SS, Peer D, Kumar P, Subramanya S, Wu H, Asthana D, Habiro K, Yang YG, Manjunath N, Shimaoka M, Shankar P: RNAi-mediated CCR5 silencing by LFA-1-targeted nanoparticles prevents HIV infection in BLT mice. Mol Ther 2010, 18:370-376.

59. Lan P, Tonomura N, Shimizu A, Wang S, Yang YG: Reconstitution of a functional human immune system in immunodeficient mice through combined human fetal thymus/liver and CD34+ cell transplantation. Blood 2006, 108:487-492.

60. Rajesh D, Zhou Y, Jankowska-Gan E, Roenneburg DA, Dart ML, Torrealba J, Burlingham WJ: Th1 and Th17 immunocompetence in humanized NOD/ SCID/IL2rgammanull mice. Hum Immunol 2010, 71:551-559.

61. Gibbs JS, Regier DA, Desrosiers RC: Construction and in vitro properties of HIV-1 mutants with deletions in "nonessential" genes. AIDS Res Hum Retroviruses 1994, 10:343-350.

62. Arora VK, Molina RP, Foster JL, Blakemore JL, Chernoff J, Fredericksen BL, Garcia JV: Lentivirus Nef specifically activates Pak2. J Virol 2000, 74:11081-11087.

63. Wei BL, Denton PW, O'Neill E, Luo T, Foster JL, Garcia JV: Inhibition of lysosome and proteasome function enhances human immunodeficiency virus type 1 infection. J Virol 2005, 79:5705-5712.

64. Palmer S, Wiegand AP, Maldarelli F, Bazmi H, Mican JM, Polis M, Dewar RL, Planta A, Liu S, Metcalf JA, et al: New real-time reverse transcriptaseinitiated PCR assay with single-copy sensitivity for human immunodeficiency virus type 1 RNA in plasma. J Clin Microbiol 2003, 41:4531-4536.

65. Estable MC, Bell B, Merzouki A, Montaner JS, O'Shaughnessy MV, Sadowski IJ: Human immunodeficiency virus type 1 long terminal repeat variants from 42 patients representing all stages of infection display a wide range of sequence polymorphism and transcription activity. J Virol 1996 70:4053-4062.

66. Lu YC, Touzjian N, Stenzel M, Dorfman T, Sodroski JG, Haseltine WA: Identification of cis-acting repressive sequences within the negative regulatory element of human immunodeficiency virus type 1. J Virol 1990, 64:5226-5229.

67. Chen J, Malcolm T, Estable MC, Roeder RG, Sadowski I: TFIl-I regulates induction of chromosomally integrated human immunodeficiency virus type 1 long terminal repeat in cooperation with USF. J Virol 2005, 79:4396-4406.

68. Bates DL, Barthel KK, Wu Y, Kalhor R, Stroud JC, Giffin MJ, Chen L: Crystal structure of NFAT bound to the HIV-1 LTR tandem kappaB enhancer element. Structure 2008, 16:684-694.

69. Markovitz DM, Smith MJ, Hilfinger J, Hannibal MC, Petryniak B, Nabel GJ: Activation of the human immunodeficiency virus type 2 enhancer is dependent on purine box and kappa B regulatory elements. J Virol 1992, 66:5479-5484.

70. Cooney AJ, Tsai SY, O'Malley BW, Tsai MJ: Chicken ovalbumin upstream promoter transcription factor binds to a negative regulatory region in the human immunodeficiency virus type 1 long terminal repeat. J Virol 1991, 65:2853-2860.

71. O'Neill E, Kuo LS, Krisko JF, Tomchick DR, Garcia JV, Foster JL: Dynamic evolution of the human immunodeficiency virus type 1 pathogenic factor, Nef. J Virol 2006, 80:1311-1320.

doi:10.1186/1742-4690-9-44

Cite this article as: Zou et al:: Nef functions in BLT mice to enhance HIV1 replication and deplete $\mathrm{CD}^{+} \mathrm{CD}^{+}$thymocytes. Retrovirology 2012 9:44. 